\title{
CRÓNICA DE LA TRAMITACIÓN DE UN PROYECTO DE COnCordato entre Chile y la Santa Sede en 1928
}

\author{
[Chronicle of a Concordat Project Processing between Chile \\ and the Holy See in 1928]
}

\author{
Carlos Salinas Araneda* \\ Pontificia Universidad Católica de Valparaíso**
}

\begin{abstract}
RESUMEN
Cuando en 1925 se produjo la separación entre la Iglesia y el Estado en Chile, hubo conversaciones dirigidas a la celebración de un concordato entre la República de Chile y la Santa Sede. Hasta ahora no se conocía algún proyecto en ese sentido. La apertura del Archivo Secreto Vaticano en lo referido a los fondos del pontificado de Pío XI ha permitido conocer los proyectos de concordato redactados en 1928. Junto a ellos se encuentra una Crónica elaborada por un testigo que vivió de cerca las gestiones hechas en Chile a tal fin, hasta que las
\end{abstract}

\begin{abstract}
In 1925, when the separation of Church and State took place in Chile, there were discussions aimed at having the Republic of Chile and the Holy See entering into a concordat. No project of such content had been known to date. The opening of the Vatican Secret Archives regarding the funds of Pius XI Pontificate, has allowed us become acquainted with the concordat projects drafted in 1928. A Chronicle written by a witness, who was closely involved in the proceedings carried out in Chile to that end until the parties abandoned the efforts,
\end{abstract}

RECIBIDO el 9 de septiembre de 2013 y ACEPTADO 26 de julio de 2014

* Catedrático de Historia del Derecho y Derecho Canónico en la Pontificia Universidad Católica de Valparaíso. Dirección postal: Pontificia Universidad Católica de Valparaíso, Facultad de Derecho, Avenida Brasil 2950, Valparaíso, Chile. Correo electrónico: csalinas@ucv.cl

** Esta investigación ha sido realizada con ocasión del Proyecto FONDECYT 1120345 del que su autor es investigador responsable. 
partes dejaron de actuar. Se publica dicha Crónica, con una introducción y con notas explicativas.

Palabras clave

Concordato - Iglesia-Estado en Chile - proyectos chilenos de concordato (1928) - Arzobispo Crescente Errázuriz - Nuncio Ettore Felici. was found together with these documents. This is a publication of the aforementioned Chronicle with an introduction and explanatory notes.

\section{KeYWORDS}

Concordat - Church - The State in Chile - Chilean concordat projects (1928) - Archbishop Crescente Errázuriz - Nuncio Ettore Felici.

\section{INTRODUCCIÓN}

Con ocasión de las conversaciones sostenidas por el presidente de la República de entonces, Arturo Alessandri Palma, con el secretario de Estado de Pío XI (1922-1939), el cardenal Pedro Gasparri, para proceder a la amigable separación entre la Iglesia y el Estado ocurrida en 1925, se habló de la posibilidad de un concordato entre Chile y la Santa Sede. No era la primera vez que en Chile se consideraba la posibilidad de un tal tratado internacional, pues durante el siglo XIX hubo intentos expresos en tal sentido ${ }^{1}$, pero nunca se llegó a la firma de ningún documento oficial. Algo similar ocurrió con ocasión de la Constitución de 1925, pero dicho documento finalmente tampoco materializó. Como cuenta Oviedo Cavada $^{2}$, la Santa Sede puso cinco condiciones para convenir en la separación que se solicitaba, todas las cuales se cumplieron con la excepción de la celebración del Concordato, pues el presidente Alessandri habría hecho ver la carencia de tiempo para una gestión de esa envergadura, interesado, como estaba, en aprobar prontamente la nueva Constitución.

Poco se ha sabido hasta ahora sobre el particular, si bien no han faltado antecedentes $^{3}$, algunos recientes ${ }^{4}$, que reconducen a la idea de que había habido más que buenas intenciones en orden a concluir un acuerdo formal entre Chile y la

${ }^{1}$ Oviedo Cavada, Carlos, Un siglo de relaciones entre la Santa Sede y Chile, 1822-1925, en Diplomacia, 39 (1987), pp. 18-30; ÉL MISMO, Negociaciones chilenas sobre convenios con la Santa Sede, en Finis Terrae, 19 (1958), pp. 37-53; ÉL MISMO, La misión Irarrázabal en Roma 1847-1850 (Santiago, 1962).

${ }^{2}$ Oviedo Cavada, Carlos, La jerarquía eclesiástica y la separación de la Iglesia y el Estado en 1925, en Boletín de la Academia Chilena de la Historia, 89 (1975-1976), p. 28. Las condiciones eran: i) Chile no debía convertirse en Estado ateo y, por eso, habría de obtenerse la invocación del nombre de Dios en la promulgación de la nueva Constitución; ii) la libertad de enseñanza para dar cabida a la educación particular y que, en ciertos tipos de enseñanza, se indicara su obligatoriedad, sin añadir la palabra "laica"; iii) derogación expresa de todos los abusos regalistas de la Constitución de 1833, como el patronato, el pase regio, etc.; iv) entre los pactos internacionales había de hacerse expresa mención de los concordatos; $v$ ) la celebración de un concordato y una compensación económica del Estado al suprimir el presupuesto del culto.

${ }^{3}$ P. ej., LiRA, Alejandro, Memorias (Santiago, 1950), pp. 168-183.

${ }^{4}$ González Errázuriz, Juan Ignacio, El Estado de Chile ante la Iglesia católica. ¿Existió un concordato en 1925?, en Ius Publicum, 5 (2000), pp. 47-57. 
Santa Sede. La reciente apertura, en el Archivo Secreto Vaticano, de los fondos referidos al pontificado de Pío XI decretada por el papa Benedicto XVI ${ }^{5}$, ha venido a mostrar que, efectivamente, hubo conversaciones oficiales entre el gobierno y la Santa Sede tendentes a la conclusión de un concordato, conversaciones que partieron, esta vez, por iniciativa de la Santa Sede, y que dieron origen a tres proyectos completos de concordato, dos de ellos presentados por el gobierno de Chile a consideración de la Santa Sede, lo que ocurrió en mayo de 1928; y el tercero, un contraproyecto presentado por el nuncio apostólico en Chile a partir del segundo de los proyectos presentados por el gobierno.

\section{LOS PROYECTOS DE CONCORDATO}

El 2 de enero de 1928, había presentado sus credenciales el nuncio apostólico Ettore Felici, quien, en un despacho fechado el 15 de marzo de ese mismo año dirigido al cardenal Secretario de Estado, le manifestaba que "conforme a las instrucciones que me fueron dadas antes de mi partida de Roma, no he faltado en reclamar discretamente la atención del gobierno sobre la oportunidad de un concordato" ${ }^{6}$. Agregaba el nuncio que las conversaciones que sobre la materia había tenido con diversos miembros del gabinete parecía que estaban dando resultado, al punto que el ministro de Relaciones Exteriores le había comunicado en la última audiencia que tenía redactado un proyecto de concordato del que, una vez que obtuviera la aprobación del presidente de la República, le enviaría una copia para conocer su parecer. Más aún, el mismo día el subsecretario, que había tenido oportunidad de leerlo, le había manifestado que el proyecto elaborado por el gobierno chileno, "salvo ligeras modificaciones", seguía el texto del concordato hacía poco concluido con Lituania, texto, añadía el nuncio, "que me ha parecido bien dar a conocer al ministro, para animarlo a seguir el ejemplo de la joven república" .

A la luz de estas noticias que el nuncio en Chile la proporcionaba a su superior, quedaba claro: i) que desde su llegada a Chile había intentado animar a las autoridades chilenas a celebrar un concordato, el que estaba pendiente desde la promulgación de la Constitución de 1925; ii) que eso lo hacía en cumplimiento de instrucciones que había recibido en Roma antes de su partida; iii) que para facilitar la redacción de ese concordato por parte de las autoridades chilenas, les había hecho llegar el texto del concordato que en 1927 había celebrado la Santa

${ }^{5}$ Bolletino della Sala Stampa della Santa Sede, 30 junio 2006 Nº340, en www.vatican.va [consultado el 24 de mayo de 2011].

6 "Conformemente alle istruzioni datemi prima della mia partenza da Roma, non ho mancato di richiamare discretamente lattenzione del Governo su la opportunità di un concordato", en Archivio Segreto Vaticano (= ASV), Sacra Congregazione degli Affari Ecclesiastici Straordinari (= AES), Cile 1927-1928, Pos. 283-285 PO, Fasc. 47, fols. 21-22. La traducción es mía, al igual que las siguientes.

7 "Salvo leggere modificazioni, il esto del concordato testé concluso con la Lituania, testo que avevo creduto bene portare a conoscenza del ministro, per incoraggiarlo a seguire lesempio della giovane repubblica”. Ibíd., fol. 26. 
Sede con Lituania ${ }^{8}$, animando a las autoridades chilenas a seguir el ejemplo de esta joven república.

Este interés de la Santa Sede de celebrar un concordato con Chile hay que situarlo en lo que se ha denominado "la nueva era de concordatos" finalizar la primera Guerra Mundial el panorama geográfico europeo había quedado modificado con la aparición de nuevos Estados independientes y el cambio de las fronteras de otros, lo que dio origen a un nuevo impulso en la celebración de concordatos bajo el pontificado de Pío XI que, en más de una ocasión, ha sido llamado el papa de los concordatos ${ }^{10}$. La "nueva era de los concordatos" se inició en 1922 con el concordato con el gobierno de Letonia, firmado el 30 de mayo de ese año ${ }^{11}$. Un nuevo concordato fue celebrado en 1925 entre la Santa Sede y la República de Polonia, el 10 de febrero de 1925². En 1927 fueron dos concordatos y un modus vivendi los celebrados por la Santa Sede: el primero de los concordatos fue celebrado con el Reino de Rumania, el 10 de mayo de $1927^{13}$ y el 27 de septiembre de 1927 se celebró el concordato entre la Santa Sede y el Gobierno de Lituania ${ }^{14}$. Además de los dos concordatos anteriores, el mismo año 1927, el 17 de diciembre, la Santa Sede firmó un modus vivendi con la República Checoslovaca ${ }^{15}$. Los anteriores son los concordatos que me interesan porque, al menos algunos de ellos fueron utilizados como modelos para la redacción de los proyectos que en dicha ocasión se prepararon, pero no fueron los únicos acuerdos internacionales celebrados por la Santa Sede en los primeros años del pontificado de Pío XI que son, al mismo tiempo, los años inmediatamente anteriores a la redacción de los proyectos chilenos ${ }^{16}$.

De esta manera, la iniciativa en orden a la firma de los proyectos de concordato parece que correspondió a la Santa Sede, y las fuentes de las diversas normas que contienen hay que situarlas en los concordatos celebrados por la Santa Sede en

${ }^{8}$ Su texto en Enchiridion dei concordati. Due secoli di storia dei rapporti Chiesa-Stato (Bologna, 2003), pp. 698-711, No 1386-1422.

${ }^{9}$ La expresión es de Yves de La Brière, que recoge Minnerath, Roland, L'Église catolique face aux Etats. Deux siècles de pratique concordataire 1801-2010 (Paris, 2012), p. 61.

${ }^{10}$ Stella, Giordano, Pio XI il Papa dei concordati (Milano, 2009).

${ }^{11}$ Enchiridion, cit. (n. 8), pp. 590-597, № 1147-1171.

${ }^{12}$ Ibíd., pp. 654-675, $\mathrm{N}^{\circ} 1282-1326$.

${ }^{13}$ Ibíd., pp. 680-699, $\mathrm{N}^{\circ} 1336-1385$.

${ }^{14}$ Ibíd., pp. 698-711, $\mathrm{N}^{\circ} 1386-1422$.

${ }^{15}$ Ibíd., pp. 710-715, N 1423-1430.

${ }^{16} \mathrm{~A}$ los anteriores hay que agregar el intercambio de notas y la convención con Colombia para la interpretación del artículo 17 del concordato (1923-1924). El concordato entre la Santa Sede y el Estado de Baviera, Alemania (1924). El intercambio de notas entre la Secretaría de Estado y el Consejo de Estado del Cantón de Friburgo, en Suiza (1924). Los acuerdos entre la Santa Sede y Francia acerca de los honores litúrgicos en los países donde se ejerce el protectorado religioso francés o en los países donde las capitulaciones están abrogadas o no se aplican (1926). Y el acuerdo entre la Santa Sede y el Gobierno de Portugal para actualizar algunos aspectos del concordato de 1886 (1928), que se firmaba el 15 de abril de 1928, es decir, pocos días antes de la presentación de los proyectos chilenos, ninguno de los cuales interesa a este estudio ya por lo específico de las materias reguladas, ya porque es muy probable que su texto, como el portugués, no hubiese sido conocido en Chile al tiempo de la redacción de sus proyectos. 
los años inmediatamente anteriores, en particular, el concordato celebrado con Lituania en 1927 al que los dos proyectos preparados por el gobierno de Chile siguen de cerca. Por su parte, el concordato con Lituania tiene su fuente en el concordato que en 1925 la Santa Sede había firmado con Polonia, el que también fue consultado por las autoridades chilenas porque algunos artículos de los proyectos chilenos se alejan de su modelo lituano y se acercan al polaco.

En 1928 era presidente de la República, Carlos Ibáñez del Campo (19271931); ministro de Relaciones Exteriores, Conrado Ríos Gallardo (1896$1983)^{17}$; y embajador de Chile ante la Santa Sede, Ramón Subercaseaux Vicuña $(1854-1937)^{18}$. Secretario de Estado de Pío XI era el cardenal Pedro Gasparri $(1852-1934)^{19}$ y nuncio apostólico en Chile el arzobispo Ettore Felici Faggiolo $(1881-1951)^{20}$.

${ }^{17}$ Conrado Ríos Gallardo nació en Santiago el 14 de mayo de 1896. Estudió derecho en la Universidad de Chile. Trabajó en el diario La Nación donde alcanzó el cargo de redactor-jefe. Fue ministro de Relaciones Exteriores del 9 de febrero de 1927 al 31 de agosto de 1929, período durante el cual se solucionó el litigio con Perú, firmándose el tratado de Lima el 28 de julio de 1929. Fue ministro interino de Fomento en 1928 y ministro subrogante del Interior en 1929. Fue embajador de Chile en España en 1929 y en Perú en 1930. Fue también embajador en Argentina. Uno de los fundadores de la revista Hoy. Fue académico de número de la Academia Chilena de la Historia y miembro de la masonería. Falleció en Santiago el 21 de julio de 1983. De Ramón, Armando y otros, Biografias de chilenos. Miembros de los poderes Ejecutivo, Legislativo y Judicial (Santiago, 2003), IV, pp. 31-32, con bibliografía.

${ }^{18}$ Ramón Subercaseaux Vicuña nació en Valparaíso el 10 de abril de 1854. Estudió leyes en la Universidad de Chile y paralelamente recibió lecciones de pintura, dejando sus estudios jurídicos por la pintura. Fue miembro del partido conservador, diputado suplente por Angol (1879-1882) y senador por Arauco (1906-1912); fue ministro de Relaciones Exteriores (1915-1916) durante el gobierno de Juan Luis Sanfuentes. Fue embajador de Chile ante la Santa Sede entre 1924 y 1930. Autor de libros y pintor, recibió diversas condecoraciones. Falleció en Viña del Mar, el 19 de enero de 1937. De Ramón, Armando y otros, cit. (n. 17), IV, p. 164, con bibliografía.

${ }^{19}$ Pedro Gasparri nació el 5 de mayo de 1852 en Capovallazza, parroquia de Usiíta, diócesis de Norcia, Italia. Estudió en el seminario de Nepi hasta 1870 y después en el Seminario Pontificio Romano y en el Pontificio Ateneo S. Apollinare, doctorándose en teología, en filosofía y en ambos derechos, canónico y civil. Fue ordenado sacerdote el 31 de marzo de 1877 en Roma. Entre otras actividades, enseñó historia de la Iglesia y teología en el Seminario Pontificio Romano y derecho canónico en el Pontificio Ateneo Urbaniano de Propaganda Fide, en el Pontificio Ateneo de S. Apollinare y en el Instituto Católico de Paris. El papa León XIII (1878-1903) lo eligió arzobispo titular de Cesarea de Palestina el 2 de enero de 1898. Fue consagrado en Paris el 6 de marzo de 1898. Entre las diversas actividades que realizó fue secretario de la Comisión Pontificia encargada de la codificación del derecho canónico. Fue creado cardenal presbítero por san Pío X (1903-1914) en el consistorio del 16 de diciembre de 1907, recibiendo el capelo cardenalicio y el título de S. Bernardo in Terme el 19 de diciembre de 1907. Participó en el cónclave de 1914 que eligió a Benedicto XV (1914-1922) que lo nombró secretario de Estado el 13 de octubre de 1914. Participó igualmente en el cónclave siguiente que eligió a Pío XI (1922-1939) quien lo nombró nuevamente secretario de Estado. En tal calidad participó en las negociaciones con el gobierno de Italia que condujeron a la firma de los Pactos de Letrán, y en las conversaciones con el presidente chileno Arturo Alessandri Palma en orden a la separación Iglesia-Estado consagrada en la Constitución de 1925. Se desempeñó como secretario de Estado hasta el 7 de febrero de 1930. Falleció en Roma el 18 de noviembre de 1934.

${ }^{20}$ Ettore Felici Faggiolo nació en Segni, Italia, el 12 de marzo de 1881. Estudió en el seminario de Segni y el Pontificio Ateneo S. Apollinare de Roma, doctorándose en filosofía, en 


\section{El "Proyecto I".}

El martes 1 de mayo de 1928, el embajador de Chile ante la Santa Sede hizo entrega en el Vaticano de un proyecto de concordato, diciendo que tenía instrucciones de pedir el parecer de la Secretaría de Estado y que regresaría el viernes siguiente a recibir la respuesta. Así quedó consignado en un pro-memoria redactado al día siguiente, el 2 de mayo, por el cardenal secretario de Estado, texto en el que se agregaba que dicho secretario de Estado había examinado el concordato y había hecho relación de él al Santo Padre. A este texto, el primero de los tres elaborados, lo denominaré "Proyecto I"21. En él llaman la atención las pretensiones neo-regalistas del gobierno de Chile que buscaba, ahora por la vía de un acuerdo internacional, recuperar parte de las atribuciones que, en relación con la Iglesia, había perdido como consecuencia de la separación Iglesia-Estado operada por la Constitución de 1925.

\section{El "Proyecto II".}

En despacho enviado por el nuncio al cardenal secretario de Estado el miércoles 30 de mayo de $1928^{22}$, le comunicaba que, en audiencia que le había concedido el ministro de Relaciones Exteriores al nuncio el miércoles anterior, 23 de mayo, le había hecho entrega del esperado proyecto de concordato; al mismo tiempo, el ministro le había pedido que lo examinara y le había solicitado que se lo restituyera lo más pronto, acompañado de sus observaciones. Este proyecto, que denominaré el "Proyecto II", constaba de 27 artículos, dos artículos menos que el "Proyecto I" y en él se acentuaban las pretensiones neo-regalistas del gobierno manifestadas en el "Proyecto I".

\section{El contra-proyecto del nuncio. (“Proyecto III”).}

Cuando el ministro de Relaciones Exteriores entregó informalmente al nuncio el "Proyecto II" y le pidió que le hiciera llegar sus observaciones, el embajador papal le respondió que no podía entrar ni directa ni indirectamente en negociaciones, estando autorizado sólo para recibir el proyecto a efectos de transmitirlo a Roma. Como el ministro insistiera en su deseo de conocer el parecer del nuncio

teología y en derecho canónico. Ingresó al servicio diplomático donde se desempeñó sucesivamente como adicto, secretario y auditor, sirviendo en las nunciaturas de Yugoslavia, Portugal y Chile. Pío XI (1922-1939) lo eligió arzobispo titular de Corinto y nuncio apostólico en Chile el 6 de noviembre de 1927, siendo consagrado en Santiago, el 30 de diciembre de 1927. Presentó sus credenciales el 2 de enero de 1928 al presidente Carlos Ibáñez del Campo. Cesó en sus funciones en Chile al ser trasladado a la nunciatura de Yugoslavia el 20 de abril de 1938, donde permaneció hasta la entrada de las tropas alemanas. Trabajó en la Secretaría de Estado en el Vaticano, conservando su título de nuncio en Yugoslavia hasta 1946. En 1949 fue nombrado nuncio en Irlanda, falleciendo en Dublín, Irlanda, el 9 de mayo de 1951. Está sepultado en la pro-catedral de Dublín. Véase: Oviedo Cavada, Carlos, Los obispos de Chile (Santiago, 1996), p. 120; Ducasse Medina, Ignacio, Servidores del Evangelio. Los obispos de Chile 1561-2007 (Santiago, 2008), pp. 154-155.

${ }^{21}$ Salinas Araneda, Carlos, Un primer proyecto de concordato entre Chile y la Santa Sede en 1928, en Revista Chilena de Derecho, 39 (2012) 3, pp. 665-698.

${ }^{22}$ ASV. AES., Cile, 1927-1928, Pos. 283-285 PO., Fasc. 47, ff. 43-46. 
antes de hacer entrega oficial del documento, el nuncio, temiendo alterar la buena disposición del secretario de Estado, consideró oportuno acceder a su petición, después de haberle hecho presente: i) que sus observaciones tendrían sólo el carácter de una consulta estrictamente personal; ii) que las opiniones expresadas por el nuncio no implicaban en modo alguno a la Santa Sede; iii) que la eventual tratativa entre el Vaticano y la Moneda se desarrollarían como si el nuncio no hubiese intervenido en el asunto ${ }^{23}$.

Con dichas reservas el nuncio aceptó el proyecto, examinándolo rápidamente la misma tarde, advirtiendo con sorpresa, que "lejos de respetar los derechos y la libertad de la Iglesia, contenía cláusulas peligrosas y disposiciones absolutamente inaceptables" ${ }^{24}$, de manera que "todo sumado el gobierno se aseguraría notables ventajas y la Iglesia vendría a encontrarse en una condición peor que la actual" ${ }^{25}$. Es por lo que, valiéndose de la libertad que le confería el carácter de consultor privado del gobierno, el nuncio modificó "sin piedad" -las palabras son suyas- el proyecto y lo restituyó al ministro junto al texto primitivo. El mismo día tuvo una larga conversación con el subsecretario, a quien explicó detalladamente los cambios introducidos a efectos de que él pudiese, a su vez, justificarlos y defenderlos ante el canciller.

El contraproyecto presentado por el nuncio, que denominaré "Proyecto III", está distribuido en el mismo número de artículos que el "Proyecto II", esto es, 27 artículos, pero no significó una mera repetición corregida de este último, pues hubo artículos de éste que fueron eliminados, se agregaron otros y la mayoría restante sufrió algunas modificaciones en su redacción, permaneciendo sin cambio alguno sólo ocho de los 27 artículos originales. Del análisis del nuevo articulado aparece que el interés del nuncio fue doble: por una parte, afirmar la personalidad jurídica de derecho público de la Iglesia y de sus entes; y, por otra, disminuir los excesos neo-regalistas del "Proyecto II", pero sólo disminuir, pues permanecieron en el contraproyecto del nuncio algunos resabios regalistas, como el juramento de los obispos.

\section{Destino de estos proyectos.}

En el pro-memoria redactado por el cardenal secretario de Estado de la audiencia que había tenido con el papa en la que había dado cuenta del primero de los tres proyectos, después de dejar constancia de la relación que había hecho del proyecto al papa, agregaba que del examen de mismo aparecía que "el gobierno no concede nada o casi nada; mientras pide muchisimas cosas, no obstante el régimen de separación". Y una vez que el papa se enteró del mimo, había dicho al cardenal que respondiese con las siguientes palabras que le había dictado: "así planteado el

\footnotetext{
${ }^{23}$ Ibíd., ff. 43-44.

24 "[...] lungi dal rispettare i diritti e la libertá della Chiesa, conteneva clausole pericolose e disposizioni assolutamente inaccettabili". Ibíd.

25 "Tutto sommato il Governo si assicurerebbe notevoli vantaggi e la Chiesa verrebbe a trovarsi in una condizione peggiore della attuale". Ibíd.
} 
concordato, no se ve para la Santa Sede la oportunidad de hacerlo. Podemos ir viviendo sin concordato". El papa había agregado que esto se debía decir por buena táctica ${ }^{26}$.

La decisión pontificia de no seguir adelante con las gestiones concordatarias, al menos sobre la base del proyecto presentado por Chile, el que he denominado "Proyecto I", era, al parecer, desconocida por el nuncio, quien, por lo demás, parece que tampoco tuvo conocimiento de dicho proyecto I y sólo había tenido acceso al segundo de los proyectos redactados por el gobierno. ¿Cuál fue el futuro de estos proyectos en Chile, supuesto que aún se desconocía la reacción pontificia? La respuesta la proporciona un documento escrito nada más haber fracasado las gestiones conducentes al proyectado concordato, que se encuentra en el Archivo Secreto Vaticano, en el fondo de documentos pertenecientes a la nunciatura de Chile en tiempos en que era nuncio Ettore Felici ${ }^{27}$.

El autor de este documento pretendió "consignar todas las gestiones a incidentes que yo conozco relativas a la gestación y tramitación del concordato proyectado entre la Santa Sede y el gobierno de Chile". Él tuvo conocimiento muy directo de los hechos que quedaron consignadas en el texto, pues, como él mismo lo reconoce, el nuncio le había "pedido que le ayudara en la nunciatura como secretario, aunque sin carácter oficial'. Y la actitud con que lo escribe es estampar "casi exclusivamente los hechos en que me ha cabido tener alguna intervención personal y sólo accidentalmente haré algún comentario. Procuraré en conciencia dar la más perfecta exactitud a la relación de los hechos y la mayor imparcialidad a las apreciaciones que sea menester hacer sobre ellos".

Una apretada síntesis de las gestiones narradas en estas páginas es la siguiente: i) una vez que el nuncio presentó el que he denominado "Proyecto III" al gobierno de Chile, redactado por él a partir del "Proyecto II" del gobierno, empezaron a aparecer en la prensa noticias sobre proyectos de ley impulsados por éste que regulaban materias en sentido diverso al que aparecían tratadas en el "Proyecto III", como la precedencia obligatoria del matrimonio civil al religioso o contribuciones exorbitantes a los inmuebles eclesiásticos; ii) ante esto el nuncio le manifestó al ministro de Relaciones Exteriores su extrañeza por la actitud del gobierno, quien le invitó a poner por escrito sus observaciones; iii) la nota redactada por el nuncio fue la excusa para que el ministro de Hacienda, con gran influjo en el presidente de la República, hiciera fracasar el proyecto, con lo que, al mismo tiempo, asestaba un golpe al ministro de Relaciones Exteriores, con quien no se llevaba bien; iv) por influjo del ministro de Hacienda, el presidente de la República dio por terminadas las conversaciones; $v$ ) paralizadas las gestiones, el autor de la crónica, con la finalidad de superar la paralización de las mismas, le sugirió al nuncio que incorporara en ellas al arzobispo de Santiago, que hasta el momento había permanecido al margen por pedirlo así el gobierno; vi) el arzobispo aceptó par-

26 "Ho esaminato il testo e Pho riferito al Santo Padre: il governo non accorda niente o quasi niente; mentre domanda moltissime cose, non ostante il regime di separazione. Il Santo Padre mi ha detto di rispondere con le seguenti parole que mi ha dettate: 'Cosi impostato il concordato non si vede per la Santa Sede lopportunitá di farlo. Possiamo tirare innanzi senza concordato'. Il Santo Padre ha aggiunto che questo si debe dire per buona tattica". Ibíd., f. 28.

${ }^{27}$ Archivio Segreto Vaticano, Arch. Nunziatura Apostolica in Cile, fasc. 155, ff. 366-390. 
ticipar, disponiendo la redacción de un nuevo proyecto, el que fue presentado al gobierno; vii) el gobierno le comunicó informalmente al nuncio que no estaba de acuerdo con algunos puntos del proyecto, como la personalidad jurídica de derecho público de la Iglesia o el reconocimiento de los efectos civiles del matrimonio; el gobierno aceptaba la enseñanza de religiosa en los colegios, pero pagada por la Iglesia. Ante esto el nuncio entendió que era mejor desistir del concordato; viii) la actitud del arzobispo fue oscilante entre el entusiasmo inicial y el pesimismo, pasando por períodos de suspicacia respecto del nuncio, alejándose del proyecto en la medida que, el paso de los meses, mostraba la renuencia del gobierno a llegar a un acuerdo, al menos en los términos propuestos por la Iglesia. Tampoco se veía poco entusiasmo en los colaboradores inmediatos del arzobispo; $i x$ ) al término de un año de iniciadas las gestiones, las dos partes dejaron de actuar.

A través de las páginas de esta crónica se puede advertir las dudas que embargaban a los personeros de la Iglesia chilena una vez producida la separación Iglesia-Estado, llevada adelante por el Estado con ocasión de la Constitución de 1925, especialmente en lo referido a la personalidad jurídica de derecho público de la Iglesia y a los bienes. De hecho, el tema de la personalidad jurídica de la Iglesia era uno de los que más preocupaba al nuncio Felici, lo que queda de manifiesto tanto en la correspondencia que durante estos meses mantuvo con el cardenal secretario de Estado, como del texto de esta crónica que ahora presento.

Pero también muestran, por una parte, los esfuerzos llevados adelante por el nuncio para llevar a buen término las gestiones de concluir un concordato que él mismo había sugerido, cumpliendo instrucciones que había recibido en Roma. Y, por otra, a un arzobispo, ya avanzado en años, susceptible, titubeante y contradictorio, y una curia diocesana escéptica y poco colaboradora frente al concordato. Parece que el nuncio era el único entusiasmado con un posible acuerdo de esta naturaleza, pero poco podía hacer si tanto el gobierno como la curia santiaguina no mostraban el mismo entusiasmo. Las gestiones para llegar a un concordato con la Santa Sede duraron casi un año exacto antes de finalizar sin el resultado esperado.

\section{EDICIÓN DE LA CRÓNICA}

El documento, de 25 páginas, numeradas a mano en la parte superior derecha, está escrito a máquina, en hojas lineadas tamaño carta, sin título y sin firma. Por una referencia hecha en el texto, queda claro que su autor fue el párroco de la parroquia del Sagrario, en Santiago, que por ese tiempo era el presbítero Pedro José Infante Fernández ${ }^{28}$. El documento tampoco lleva fecha, pero de su conte-

${ }^{28}$ Pedro José Infante Fernández nació en Santiago el 16 de abril de 1861. Ordenado presbítero el 22 de diciembre de 1883, continuó en el Seminario de Santiago como prefecto de piedad. Fue párroco de la parroquia del Sagrario, contigua a la catedral de Santiago, por 29 años. Privado de esa responsabilidad por acusaciones en su contra, una vez que se demostró la falsedad de las mismas, volvió como párroco a la misma parroquia. En 1907 fundó la Unión Nacional de Obreros, que contó con más de 6.000 asociados. Fundó, además, seis escuelas, en Santiago, Valparaíso, Limache, Quillota y Olmué. Falleció en Santiago, el 26 de octubre de 
nido se desprende que tiene que haberse escrito no más allá de mayo o junio de 1929, pues está redactado en fecha muy próxima a la definitiva conclusión de las gestiones, lo que ocurre en el mes de mayo de 1929, exactamente un año después de haberse presentado el primero de los proyectos.

El documento presenta algunas tachaduras hechas con tinta, manuscribiéndose entre líneas las palabras que sustituyen a las palabras tarjadas; en cada caso he dejado constancia de esta circunstancia. He actualizado la ortografía y la puntuación y, cuando me ha parecido oportuno, he agregado algunas notas que facilitan la comprensión del texto.

\section{[Crónica de las gestiones llevadas adelante en Santiago de Chile para firmar un Concordato entre Chile y la Santa Sede en 1929]}

\section{“[1.] Tramitación del concordato ${ }^{29}$}

"En estas páginas voy a consignar todas las gestiones e incidentes que yo conozco $^{30}$ relativas a la gestación y tramitación del concordato proyectado entre la Santa Sede y el gobierno de Chile. Estamparé casi exclusivamente los hechos en que me ha cabido tener alguna intervención personal y sólo accidentalmente haré algún comentario. Procuraré en conciencia dar la más perfecta exactitud a la relación de los hechos y $\mathrm{la}^{31}$ mayor imparcialidad a las apreciaciones que sea menester hacer sobre ellos.

\section{“[2.] Antecedentes}

"El Exmo. señor nuncio, don Héctor Felici, llegado a Chile como encargado de negocios en junio de 1927 y designado nuncio de la Santa Sede en noviembre del mismo año, se dio cuenta muy pronto de la situación incierta y peligrosa en que habían quedado los intereses de la Iglesia, después de la reforma de la Constitución del año 1925 y de la separación de la Iglesia del Estado. Su antecesor, monseñor Aloysi Masella ${ }^{32}$, diplomático afortunado en otras gestiones, aceptó el

1941. Arancibia Salcedo, Raymundo, Diccionario biográfico del clero secular de Chile: 19181969 (Santiago, 1969), pp. 105-106.

${ }^{29}$ En el original con letras mayúsculas.

${ }^{30}$ Las palabras "que yo conozco" están escritas en mayúscula en el original.

${ }^{31} \mathrm{El}$ artículo "la" está repetido en el original.

${ }^{32}$ Benedetto Aloisi Masella nació en Pontecorvo, Italia, el 29 de junio de 1879. Estudió en el Seminario de Ferentino y en la Universidad Gregoria de Roma, doctorándose en filosofía, teología y derecho canónico. En el Pontificio Ateneo Apollinare se doctoró in utroque iure, en ambos derechos, canónico y civil. Además hizo estudios diplomáticos en la Academia de Nobles de Roma. Fue ordenado prebítero el 1 de junio de 1902, después de lo cual se desempeñó como secretario de la nunciatura en Portugal (1908) y como auditor y encargado de negocios de la misma nunciatura (1910-1919). Benedicto XV (1914-1922) lo eligió arzobispo titular de Cesarea de Mauritania el 15 de diciembre de 1919, siendo consagrado en Roma el 21 de diciembre siguiente. El mismo Romano Pontífice lo había nombrado nuncio apostólico en Chile el 20 de noviembre de 1919, presentando sus credenciales al presidente Juan Luis Sanfuentes en abril de 1920; fue trasladado como nuncio a Brasil el 26 de abril de 1927, cargo que ejerció hasta que el papa Pío XII (1939-1958) lo creó cardenal presbítero en el consistorio del 18 de febrero de 1946, recibiendo el título de S. Maria in Vallicella; posteriormente fue 
artículo 10 de la actual Constitución, el cual, reconociendo a la Iglesia el dominio perfecto, como institución de derecho público, para los bienes habidos con anterioridad al año 25 , deja en la duda y la ambigüedad los derechos posteriores a la promulgación de la Constitución. Los nuevos obispados creados el año $1926^{33}$ están así sometidos a la interpretación que se quiera dar en un sentido o ${ }^{34}$ en otro al artículo 10 de la Constitución. En cuanto al ejercicio del dominio. La facultad de poseer, enajenar, heredar, hipotecar, etc. es hoy día completamente incierta en esos obispados. Los señores obispos con frecuencia hacían presente al señor nuncio la situación difícil en que se encontraban. De importancia también capital para la Iglesia era la solución de los problemas relacionados con la exención de contribuciones, solución del problema del matrimonio civil y religioso, enseñanza religiosa en los colegios del Estado, etc., problemas todos estos que también quedaron sin resolver, entregados solamente a la voluntad favorable o adversa del gobierno para con la Iglesia.

"El Exmo. señor Felici, posesionado de la importancia y gravedad de estos asuntos, ideó en enero de 1928 la solución de ellos por medio de un concordato, idea que, propuesta por él al ministro de Relaciones Exteriores, fue aceptada en principio con gran interés de parte de este secretario de Estado.

"El gobierno preparó y presentó al señor nuncio un proyecto de concordato. El señor nuncio comenzó en el acto el estudio de él y con la preparación superior que todos le reconocen, consultado cada punto con las personas más competentes, presentó a su vez al gobierno el espléndido contra-proyecto en [en blanco] de 1928.

"El gobierno, por medio del ministro de Relaciones Exteriores declaró que lo aceptaba en principio; fue enviado a Roma en consulta y aprobado ampliamente con una encomiástica nota del Emmo. señor cardenal secretario de Estado.

\section{"[3.] Detalle de importancia ${ }^{35}$}

"Cuando el señor nuncio me impuso, dentro de la más absoluta reserva, de su proyecto en febrero de 1928 (habiéndome antes pedido que le ayudara en la

promovido a cardenal obispo de la diócesis suburbicaria de Palestrina. Fue prefecto de la $S$. Congregación de sacramentos, arcipreste de la basílica de San Juan de Letrán, y camarlengo de la Iglesia romana en 1958. Falleció en Roma el 30 de septiembre de 1970, siendo sepultado en la basílica de Pontecorvo. Oviedo Cavada, Carlos, Los obispos, cit, (n. 20), p. 67; Ducasse Medina, Ignacio, cit. (n. 20), p. 84.

${ }^{33}$ Mediante la constitución apostólica Apostolici muneris ratio, de 18 de octubre de 1925 [Acta Apostolicae Sedis, 18, 1926, pp. 201-204; ahora, en latín y castellano, en Retamal FuenTES, Fernando, Chilensia pontificia. Monumenta Ecclesiae Chilensia (Santiago, 2005), II, 3, pp. 1638-1645] fueron desmembrados del arzobispado de Santiago los obispados de Valparaíso, San Felipe, Rancagua y Talca. Mediante la constitución apostólica Notabiliter aucto, de 18 de octubre de 1925 (Acta Apostolicae Sedis 18, 1926, pp. 205-207; ahora, en latín y castellano, en Retamal Fuentes, Fernando, cit. esta nota, pp. 1646-1651), fueron desmembrados del obispado de Concepción los obispados de Chillán, Linares y Temuco. En atención a que ambas constituciones apostólicas fueron publicadas en los Acta del mes de junio de 1926, ello explica que se considere en la Crónica el año 1926 como el de erección de esos obispados, referencia que es inexacta.

\footnotetext{
${ }^{34}$ En el original "u".

${ }^{35}$ En el original con letras mayúsculas.
} 
nunciatura como secretario, aunque sin carácter oficial) una de las primeras observaciones que le sugerí fue acerca de si pensaba imponer al señor arzobispo del proyecto y pedirle su cooperación. Me contestó que ese punto lo había estudiado y que no lo haría por dos razones: la primera por que el ministro de $\mathrm{R}$ [relaciones] E [exteriores] le había pedido y exigido una reserva absoluta sin ninguna excepción sobre esta gestión, condición indispensable, según el ministro, para asegurar su éxito; y la segunda, porque no consideraba necesaria la cooperación del arzobispo, atendidas las seguridades de éxito y a muy corto plazo que le había dado el ministro.

\section{"[4.] El fracaso. Su causa. Los hechos ${ }^{36}$}

"Estando en este estado las negociaciones, impregnadas de optimismo muy fundado, comenzaron a aparecer en la prensa proyectos emanados del gobierno que significaban un desmentido categórico a los puntos principales del concordato. Así, el ministro de Justicia, servido entonces por D. Eduardo Barrios ${ }^{37}$, radical y masón, hacía revivir el proyecto de precedencia del matrimonio civil al religioso, imponiendo a los párrocos multas por la violación de las disposiciones de la ley en proyecto; el ministerio de Hacienda, servido por D. Pablo Ramírez ${ }^{38}$,

${ }^{36}$ Ídem.

${ }^{37}$ Juan Eduardo Barrios Hundtwalker nació en Valparaíso el 25 de octubre de 1884, hijo de Eduardo Barrios Achurra, oficial del ejército chileno e Isabel Hudtwalcker Journy, de nacionalidad peruana. Desde 1889, fecha de la muerte de su padre, vivió en Lima, ciudad en la que estudió en diversos colegios. Cuando en 1900 regresó a Chile, ingresó a la Escuela Militar donde no pudo adaptarse. Se dedicó a nuevas experiencias y desempeñó variadas actividades, como artista de circo y buscador de oro, entre otras. De regreso en Santiago en 1909, empezó a trabajar como funcionario de la Universidad de Chile y taquígrafo en la Cámara de Diputados. Fue redactor de las revistas Pluma y Lápiz, Pacífico Magazine y Zig-Zag en 1915, integrando el grupo literario de Los Diez. En 1925 ingresó a la Biblioteca Nacional, llegando pronto a ser nombrado conservador de propiedad intelectual. El 17 de noviembre de 1927 fue nombrado por el presidente Carlos Ibáñez del Campo, ministro de Instrucción Pública, siendo el primer ministro que ocupó dicha cartera, pues el ministerio de Instrucción Pública acababa de ser separado del ministerio de Justicia. A la caída del gobierno, renunció a sus cargos públicos para comenzar otra etapa, la de agricultor terrateniente, pero no descuidó la actividad literaria y continuó escribiendo en los diarios El Mercurio y La nación, como lo había hecho hasta entonces. Fue incorporado a la Academia Chilena de la Lengua en 1953 y en 1960 fue designado director de la Biblioteca Nacional, puesto que ocupó hasta jubilarse en 1960. De sus obras destacan El niño que enloqueció de amor (1915) y Gran señor y rajadiablos (1949). En 1946 obtuvo el premio nacional de literatura. La referencia que en esta Crónica se hace a que Barrios era ministro de Justicia está errada, error que puede estar originado en el hecho que poco antes de ser escrita, el Ministerio de Educación había sido separado del Ministerio de Justicia, alcanzando entidad propia. El Ministerio de Justicia, a la fecha de esta Crónica, estaba dirigido por Osvaldo Koch, nombrado por decreto de 24 de febrero de 1928. Cf. Valencia Avaria, Luis, Anales de la República (2a edición, Santiago, Andrés Bello, 1986), I, pp. 573-577.

${ }^{38}$ Pablo Ramírez Rodríguez nació en Valparaíso en 1886, ciudad en la que se educó en el colegio Mackay, primero, y en el Seminario después. Se tituló de abogado en 1908 después de cursar los cuatro primeros años de leyes en la Universidad Católica de Santiago y el quinto año en la Universidad de Chile. En 1912 fue consejero de Estado. Incorporado al partido Radical, fue elegido diputado en diversas ocasiones a partir de 1912. Entre otras actividades, fue nombrado ministro de Justicia e Instrucción Pública, cargo que desempeñó del 3 de mayo al 23 de septiembre de 1919; posteriormente fue nombrado ministro de Hacienda, ministerio 
sectario conocido y enemigo personal del ministro de Relaciones Exteriores, lanzaba a la publicidad un proyecto de contribuciones exorbitantes y absurdas a los bienes eclesiásticos. El señor nuncio, ante estos hechos para él inexplicables, desconociendo, como extranjero recién llegado al país, el juego interno de la política de la Moneda y las influencias que probablemente ya se movían detrás de bastidores contra el concordato por elementos sectarios, manifestó en el salón de una embajada su extrañeza al ministro de Relaciones [Exteriores], representante del gobierno con quien él estaba negociando, por los proyectos de ley que otros ministros del mismo gobierno presentaban, proyectos que atacaban por la base los puntos esenciales del concordato en tramitación.

"El ministro le pidió que le consignara por escrito en una nota particular las observaciones que le hacía. El señor nuncio así lo hizo y esa nota en la que, en verdad, había alguna frase que indicaba el asombro que le causaban la actitud del gobierno, fue el pretexto escogido para hacer fracasar la gestión.

"Esa nota, de la cual se hizo tanto caudal, fue previamente dada a conocer por el señor nuncio al subsecretario de Relaciones [Exteriores], quien la calificó de "buena"; también la leyó antes de su entrega, el propio ministro de Relaciones [Exteriores] quien la calificó de "espléndida". La nota, por lo demás, fue un documento privado, no oficial. Prueba de ello es el hecho de que no quedó copia en el archivo de la nunciatura, ni tenía la numeración que lleva toda nota oficial.

"¿Qué fue lo que aconteció? ¿Por los datos obtenidos se sabe que esta nota fue aprovechada astutamente por el ministro de Hacienda para dar un golpe de muerte al concordato, mal mirado por el secretario y reflejamente a su colega el ministro de Relaciones [Exteriores], su enemigo. El presidente de la República, influenciado completamente por el ministro de Hacienda, declaró que el asunto estaba terminado y que no se trataría más de concordato.

\section{"[5.] Un incidente relacionado con gestiones futuras ${ }^{39}$}

"El día [blanco] de septiembre me llamó con urgencia por teléfono mi amigo el prebendado Ladislao Godoy ${ }^{40}$. En la conversación personal que tuve con él, me

que desempeñó del 22 de febrero 1927 al 23 de mayo del mismo año, siendo confirmado en el mismo cargo y como interino de Agricultura, Industria y Colonización el 6 de septiembre de 1927; el 17 de octubre de 1928 fue nombrado ministro interino de Educación, cartera que dejó 11 de marzo de 1929 y la de Hacienda en agosto del mismo año. Desempeñó también, el cargo de Contralor General durante los primeros tiempos de la Contraloría General de la República, entre 1927 y 1929; fue abogado del Consejo de Comercio Exterior y consejero del Banco Central en 1930. Fue presidente de la representación de Chile a la Conferencia Internacional de Productores de Salitre, realizada en París, el 26 de abril de 1930. Fue delegado del gobierno de Chile en Europa y Egipto, también en 1930. Por encargo del gobierno, participó activamente, entre 1929 y 1930, en la organización de la Compañía Salitrera de Chile (COSACH), creada el 20 de marzo de 1931. Falleció en Santiago, el 11 de julio de 1949. Cf. Valencia Avaria, Luis, cit. (n. 37), pp. 571-577.

${ }^{39}$ En el original con letras mayúsculas.

${ }^{40}$ Ladislao Godoy nació en Santiago el 28 de julio de 1881. En 1896 tomó el hábito franciscano, pero se trasladó al Seminario de Santiago donde hizo todos sus estudios hasta recibir el presbiterado el 28 de abril de 1905 . Fue profesor en el Instituto de Humanidades, en el Seminario y en el colegio María Auxiliadora. Fue párroco fundador de la parroquia de Andacollo 
refirió detalladamente una entrevista muy singular que acababa de tener con el señor arzobispo por quien fue llamado. En resumen, el prelado en forma nerviosa y molesta le había hablado ${ }^{41}$ sobre la actuación del señor nuncio en el país. Se había quejado amargamente de que el señor nuncio prescindía sistemáticamente del señor arzobispo, que nada le consultaba ni lo informaba, ni siquiera le visitaba; que estaba mal rodeado y mal aconsejado y que necesitaría redactar algunas cartas muy reservadas para lo cual lo llamaría después. Godoy quedó muy impresionado de las cosas que oyó del prelado, del tono que empleó para decírselas y principalmente del asunto de redacción de ciertas cartas ${ }^{42}$ que tenía que escribir.

"Me formé la impresión de que este llamado fue una táctica (y creo no haberme equivocado, pues, cumplido el fin que perseguía el prelado, no llamó más a Godoy) para hacer llegar por un camino corto y seguro sus quejas al señor nuncio.

"En la noche de ese mismo día yo debía encontrarme con el vicario señor Miller ${ }^{43}$ en una comida, y lo mejor antes de hablar con el señor nuncio era tratar el punto con franqueza con el vicario para conocer bien el alcance de las quejas del señor arzobispo. Así lo hice. Una larga hora de conversación con el vicario me explicó todo el incidente. El único cargo fundado que tenía contra el señor nuncio consistía en que sabían que $S[\mathrm{u}] \mathrm{E}$ [xcelencia] había pronunciado en forma enérgica, contestando a una pregunta directa que sobre el particular le hizo un sacerdote, esta frase: 'Miller de ninguna manera será arzobispo de Santiago'. Las otras quejas eran más bien de carácter sentimental: que monseñor Masella lo visitaba tres veces por semana y monseñor Felici sólo lo había ${ }^{44}$ visitado cuatro veces en el año. Lo importante residía ${ }^{45}$ en esa frase que hería profundamente al vicario y también al señor arzobispo.

(1928) y párroco de la parroquia de El Salvador, desempeñándose en ambas por largos años. El arzobispo Errázuriz lo hizo canónigo honorario, oficio que ocupaba cuando ocurren los hechos descritos en esta Crónica; el cardenal Caro, lo nombró en propiedad en 1951. Antes, en 1940, había sido nombrado prelado doméstico de Su Santidad. Falleció en Santiago, el 1 de junio de 1968. Arancibia Salcedo, Raymundo, cit. (n. 28), p. 92.

${ }^{41}$ La palabra "hablado" está manuscrita, entre líneas, sobre la palabra "estos" que aparece tachada.

${ }^{42}$ Las palabras "ciertas cartas” están escritas en el original con letras mayúsculas, espaciadas y subrayadas.

${ }^{43}$ Miguel Miller nació en Santiago el 9 de junio de 1879. Fue ordenado presbítero el 20 de diciembre de 1902. Fue profesor en el Seminario de Santiago, Instituto de Humanidades, Escuela Militar y Liceo Paula Jaraquemada, y secretario de la vicaría castrense. En 1919 el arzobispo Errázuriz lo nombró secretario de cámara y, posteriormente, vicario general del arzobispado de Santiago, oficio que desempeñó desde 1926 hasta 1931. En 1924 y 1929 hizo la visita adlimina en reemplazo del prelado ya muy anciano. En 1925 ingresó al cabildo metropolitano y ese mismo año la Santa Sede lo nombró prelado doméstico. Fallecido el arzobispo Errázuriz en 1931, se retiró de toda actividad de la curia mientras fue arzobispo José Horacio Campillo Infante (1931-1939). Al ser nombrado arzobispo José María Caro (1939), lo nombró nuevamente vicario general, oficio que desempeñó hasta su muerte ocurrida en Limache el 22 de noviembre de 1945. Era comendador de la Orden de Isabel la Católica y miembro de la Facultad de Teología desde 1921. Véase: Arancibia SAlcedo, Raymundo, cit. (n. 28), pp. 140-141.

${ }^{44}$ En el original escrita a máquina solo la palabra "ha", a la que se agregó a mano el complemento "bía".

${ }^{45}$ La letra "s" está manuscrita sobre una letra "c" escrita a máquina originalmente. 
"El señor Miller me habló con un calor inusitado en su carácter de suyo frío. Se quejó de que el señor nuncio le creyera con pretensiones al arzobispado, que él no deseaba, que con esas expresiones lo colocaba como a ${ }^{46}$ un nuevo Taforó ${ }^{47}$, etc. Yo me limité a decirle que, respecto del señor arzobispo, conocía a fondo el aprecio que le tenía al señor nuncio, que si no lo visitaba más a menudo se debía a falta de asuntos de importancia de ${ }^{48}$ que tratar, a falta de tiempo en el señor nuncio que estaba solo y aún a temor de molestarlo y que sobre el otro asunto yo no sabía lo que hubiera ${ }^{49}$ sucedido, pero ${ }^{50}$ que me parecía increíble esa expresión, pues sabía cuan reservado era sobre ese tema y que me encargaría de aclarar el asunto.

"Así lo hice, en efecto, y el señor nuncio me autorizó para desmentir ante el señor Miller la frase que se le atribuía. La que había producido en esa ocasión fue la siguiente: "será arzobispo de Santiago la persona que designe la Santa Sede", expresión que nada tenía de particular y del todo diferente a la que llegó al arzobispo.

"El señor Miller aceptó la explicación, pero quedó un recelo agudo que se ha manifestado incesantemente.

"El señor nuncio, después de este incidente que se produjo en los mismos días del fracaso del concordato, visitó con mucho mayor frecuencia al señor arzobispo a fin de hacer desaparecer cualquier mal entendido.

${ }^{46}$ En el original la letra "a” está manuscrita al margen izquierdo.

${ }^{47}$ Francisco de Paula Taforó nació en Valparaíso en 1816, hijo ilegítimo de Rafael Márquez de la Plata Huidobro y María Jesús Zamora Astorga, quien estaba casada con José Ignacio Taforó, que lo reconoció como hijo. Estudió en Santiago, en el convento de Santo Domingo y en el Seminario de Santiago, del que fue profesor de latín. Fue ordenado presbítero en julio de 1839, iniciando su tarea sacerdotal en Atacama y Copiapó. De regreso en Santiago, en 1847 ingresó como miembro de la Facultad de Teología de la Universidad de Chile. Fue rector y catedrático del Liceo de Santiago y formó parte de la Sociedad de Instrucción Primaria, además de autor de varias obras entre las que destacan un Curso de historia sagrada, que alcanzó 15 ediciones, y un Catecismo elemental de la doctrina cristiana, con tres ediciones. Ingresó en el cabildo catedralicio donde llegó a ser arcediano. En 1846 fue elegido diputado por Talca y en 1849 diputado por Linares. Entre 1851 y 1855 viajó por Europa, a la que regresó en 1876. Fue consejero de Estado en 1847 y en los gobiernos de Errázuriz Zañartu, Pinto, Santa María y Balmaceda. En 1878 fue propuesto por el gobierno para reemplazar a Rafael Valentín Valdivieso como arzobispo de Santiago, proposición que originó una fuerte protesta del clero santiaguino, opuesto a las ideas liberales de Taforó. Se dio inicio, así, a un período de fuertes tensiones entre Chile y la Santa Sede, que dieron origen a una misión diplomática enviada por la Santa Sede, al frente de la cual venía Celestino del Frate, y que culminó con la ruptura de relaciones con Roma decidida por Chile. Finalmente, Taforó renunció a dicha candidatura y, tiempo después, fue nombrado Mariano Casanova al frente del arzobispado. Falleció el 27 de enero de 1889, ratificando su catolicidad. Sobre el conflicto arzobispal puede verse, por todos, AranEda Bravo, Fidel, Historia de la Iglesia en Chile (Santiago, Paulinas, 1986), pp. 564-590.

${ }^{48}$ En el original la preposición "de" está manuscrita entre líneas.

${ }^{49}$ La palabra "hubiera" está manuscrita entre líneas sobre la palabra "había", escrita a máquina, que está tarjada.

${ }^{50}$ La palabra "pero" está manuscrita entre líneas sobre la palabra "pues", escrita a máquina, que está tarjada. 


\section{“[6.] Atmósfera en el arzobispado ${ }^{51}$}

"Por mi cargo de párroco del Sagrario y otras ocupaciones que desempeño estoy en contacto diario con el arzobispado. Así, pues, durante todo el año 1928 he podido apreciar que en el arzobispado existía, se mantenía y acentuaba una atmósfera de desconfianza, de recelo y hasta de hostilidad en ciertos casos para con el señor nuncio. He oído con frecuencia las frases de quejas del señor arzobispo, repetidas a pesar de las visitas frecuentes del señor nuncio; he oído las críticas, aunque ligeras, de los vicarios y principalmente he conocido y oído la forma como el presbítero José Manuel Astorga ${ }^{52}$, el amigo íntimo y consejero de los vicarios, se expresaba del señor nuncio ante cualquier persona. Llegó a tal punto la forma procaz en ${ }^{53}$ que se refería a él que le pedí cierto día que no hablara más, por cuanto comprometía gravemente a sus dos íntimos amigos, los dos vicarios; pues todos creían que lo que él decía era eco de lo que oía a los vicarios. La razón dada lo convenció y prometió callar.

"La atmósfera en el arzobispado ha sido, desde el incidente que relaté, muy pesada para el señor nuncio.

\section{“[7.] La nueva gestión pro-concordato ${ }^{54}$}

"Desde el fracaso anteriormente relatado, el proyecto de concordato quedó sepultado y olvidado.

"En las vacaciones de 1929 se produjo el arreglo de la Cuestión Romana ${ }^{55}$ y este hecho pareció traer un soplo de optimismo para procurar nuevas gestiones.

"En el mes de febrero, preocupado de este problema, tan importante, medité un plan que resolví presentarle al señor nuncio, aunque lo veía lleno de escollos.

${ }^{51}$ En el original con letras mayúsculas.

${ }^{52}$ José Manuel Astorga nació en Santiago el 30 de mayo de 1877. Después del colegio entró a estudiar medicina, estudios que dejó para ingresar al Seminario de Santiago. Fue ordenado presbítero el 8 de abril de 1905, desempeñando labores sacerdotales en diversos lugares, Olmué, Valparaíso, San José de Maipo, Cartagena, Quilpué. Fue bibliotecario del arzobispado y miembro del tribunal de cuentas diocesanas. El arzobispo Crescente Errázuriz, de quien era gran amigo, quiso nombrarlo canónigo, nombramiento que finalmente no pudo hacerse por no ajustarse a los cánones. Murió en Santiago, el 2 de marzo de 1960. Véase: Arancibia Salcedo, Raymundo, cit. (n. 28), p. 22.

${ }^{53}$ La palabra "en" está manuscrita, entre líneas, sobre la palabra "con" escrita a máquina y que aparece tarjada.

${ }^{54}$ En el original con letras mayúsculas.

${ }^{55} \mathrm{El} 11$ de febrero de 1929 se firmaron en Roma los Pactos de Letrán, entre el papa Pío XI y Benito Mussolini, primer ministro y jefe del gobierno italiano. En virtud de un Tratado, se dio existencia al Estado de la Ciudad del Vaticano; inmediatamente se firmó un Concordato entre la Santa Sede y el Reino de Italia. Con la firma de ambos documentos se dio por concluida la Cuestión romana que, iniciada a mediados del siglo XIX, había llegado a su máxima expresión en 1870 con la entrada de las tropas italianas en Roma, momento a partir del cual el papa se consideró un prisionero en el Vaticano. El concordato firmado en 1929 sigue vigente, después de una modificación realizada en 1984. El Tratado y sus anexos, en Acta Apostolicae Sedis, 21 (1929), pp. 209-274; el Concordato, ibíd., pp. 275-294. Ahora en Enchiridion, cit. (n. 8), pp. $728-749, \mathrm{~N}^{\circ} 1460-1542$. 
El 17 de febrero le expuse a S[u] E[xcelencia] mis ideas, haciendo un prólogo entusiasta sobre el arreglo del Vaticano e Italia.

\section{"[8.] La Iglesia ante todo ${ }^{56}$}

"Voy a dejar aquí, comenzando, un detalle íntimo de esta conversación que revela el espíritu de monseñor Felici y que es su más grande honor.

"Al insinuarle el nuevo camino por donde yo veía probable que resultara el concordato, que sería la intervención directa del señor arzobispo de Santiago, con la cual se podría llegar a un éxito fácil, pues no se podía desconocer la deferencia que el gobierno tiene para con él, me detuvo, alegándome sus derechos que ${ }^{57}$, como representante de la Santa Sede, le eran propios para la tramitación de estos negocios ${ }^{58}$.

"A mi vez le expuse los intereses superiores que estaban de por medio, el bien de la Iglesia, etc., y después de un largo cambio de ideas, vi el acto edificante, uno de los más sacerdotales que he visto en mi vida, que se convencía plenamente que por amor a la Iglesia y por salvar sus intereses debía sacrificar sus derechos personales, por legítimos que fueran. Me dijo: "Yo pediré al señor arzobispo de Santiago que tome en sus manos el concordato; que mueva sus poderosas influencias y si obtiene el triunfo yo seré el primero en besarle la mano y comunicar al papa que el concordato ha resultado gracias, en parte ${ }^{59}$, a las influencias del señor arzobispo".

"Al día siguiente, me confirmó que estaba decidido, después de mucha meditación, a tomar ese camino.

\section{“[9.] Preparando el terreno ${ }^{60}$}

"Yo conocía perfectamente, como he dicho antes, la atmósfera que, aunque del todo injustificada ${ }^{61}$, rodeaba al señor nuncio en el arzobispado que era como de plomo y era fácil deducir que no sería mejor la que tuviera ante el prelado que está rodeado solamente de muy pocas personas. Era, por lo tanto, elemental para asegurar el éxito, disipar todas las prevenciones que ciertamente existirían en el ánimo del prelado, tarea de que me encargué yo.

"En mi primera visita a él, que por casualidad fue hecha en compañía de mons[eñor] Luis Camplino ${ }^{62}$, el señor arzobispo pronto puso el tema de los nuncios

${ }^{56}$ En el original con letras mayúsculas.

${ }^{57}$ La palabra "que" está manuscrita, entre líneas, pues falta en el original escrito a máquina.

${ }^{58}$ Las palabras “con el arzobispado” escritas a máquina a continuación están tarjadas.

${ }^{59}$ La expresión “en parte” no aparece en el original escrito a máquina, sino que está añadida manuscrita, entre líneas.

${ }^{60}$ En el original con letras mayúsculas.

${ }^{61}$ La frase "aunque del todo injustificada” está añadida manuscrita, entre líneas.

${ }^{62}$ El apellido es "Campino" y no "Camplino" como está escrito en la Crónica. Luis Campino Larraín nació en Santiago el 28 de mayo de 1851, hijo de Miguel Campino Landa y Luisa Larraín Gandarillas, hermana del obispo Joaquín Larraín Gandarillas. Fue ordenado presbítero el 30 de noviembre de 1873. Fue profesor en el Seminario. En 1897 fue nombrado procurador del Colegio Pío Latino y en diciembre de 1889 rector del Instituto de Humanidades que acababa de fundar el arzobispo Casanova, colegio que dirigió durante 18 años y que hoy lleva su nombre. En 1903 fue nombrado canónigo del cabildo catedralicio, oficio que desempeñaba 
(él conoce muy bien la relación de amistad que yo tengo con el señor nuncio). Habló muy largamente sobre los fracasos que aquí han tenido otros nuncios; sobre las dificultades que se les presentan; sobre el poder tan grande y a la vez tan lleno de peligros de que están investidos, si no proceden con gran tino y discreción, principalmente en la provisión de obispado y más aún del arzobispado; que por eso era tan útil 'la intervención moderada del gobierno'. Este fue el momento que aproveché para mi objeto. 'Siempre que haya un concordato ${ }^{63}$ de por medio ${ }^{64}$, le dije. ¿No cree S[u] S[eñoría] que fuera posible obtenerlo ahora que la solución de la Cuestión Romana forma un buen ambiente a estos convenios ${ }^{65}$ ?' Recordó entonces las gestiones anteriores y el fracaso y se manifestó muy pesimista sobre la posibilidad de reanudarlas.

"Yo bien comprendí el alcance que el señor arzobispo daba a su conversación y di gracias a Dios de que la puerta me quedara abierta para volver a tratar el asunto y llevarlo al punto que se necesitaba.

"En una segunda visita que, muy pronto le hice, le hablé y él me escuchó con gran atención acerca de cómo entendía yo las relaciones de amistad con personas de tanta influencia, como es un nuncio, y en cuyo ánimo puedan pesar algo las opiniones que oiga; le hablé de que las bases eran ante todo la imparcialidad y que me imaginaba que a las pruebas que de ella le había dado en todo caso, debía tal vez la confianza con que me distinguía; la franqueza respetuosa para exponerle las opiniones aunque fuesen a veces ${ }^{66}$ contrarias a las suyas y la lealtad al arzobispo de la cual podía señalarle pruebas muy concretas. El señor arzobispo aprobó completamente mi actitud. Se había caminado un paso más; que el prelado tuviera confianza en mi modesta intervención.

"En otra visita ya abordé resueltamente el punto de sus relaciones con el señor nuncio. Estuvo franco y comunicativo; me expresó las quejas que tenía en contra de él; la falta de contacto con él, cargo que le expliqué por las causas antes dichas; la ignorancia en que él estuvo acerca del concordato, cuya existencia conoció por otras personas, cargo que le desvanecí con las dos razones que el señor nuncio me dio en su oportunidad, a saber, el secreto exigido por el ministro de Relaciones Exteriores y la seguridad del éxito que le había dado ${ }^{67}$. Este era el momento, deshechas esas y otras dudas, para abordar el proyecto del señor nuncio y se lo expuse franca y detalladamente. Ya el señor nuncio algo le había insinuado personalmente el día anterior. Todos los detalles que le di, no podían menos de impresionarle y reconocer la elevación de miras, el espíritu sacerdotal y la sinceridad con que

cuando ocurrieron los hechos descritos en la Crónica, llegando a ser deán del mismo. En 1923 fue consejero de Estado y en 1927 el papa Pío XI lo nombró protonotario apostólico. Murió en Santiago, el 25 de agosto de 1929. Véase: Arancibia Salcedo, Raymundo, cit. (n. 28), p. 38.

${ }^{63}$ La palabra "concordato" está escrita a máquina, entre líneas, sobre la palabra "Con...o" también escrita a máquina, la que está tajada con la misma máquina de escribir.

${ }^{64} \mathrm{La}$ frase "de por medio" está repetida en el original escrito a máquina; la frase repetida está tarjada a mano.

${ }^{65}$ En el original, escrita a máquina está la palabra "Concordatos", la que está tarjada a mano y sobre ellas, manuscrita entre líneas, la palabra "convenios".

${ }^{66}$ Las palabras "a veces” están añadidas manuscritas entre líneas.

${ }^{67}$ La palabra "dado" está manuscrita, entre líneas, sobre la palabra “asegurado” que está tarjada. 
procedía el señor nuncio y estas ideas me las manifestó en repetidas formas. Me dijo que él tomaría con todo interés el asunto que el señor nuncio le iba a encomendar, que movería todas sus influencias, que, si era menester, llamaría de a uno a los ministros para pedirles que, antes de morir, le dieran la satisfacción de ver el concordato y que creía en un feliz resultado. Imposible era desear una mejor acogida. El señor nuncio habló en esos días varias veces con el prelado y le repitió, con el mayor entusiasmo, su interés de llevar a cabo el concordato; acordaron que el arzobispo estudiaría una fórmula que, a juicio del señor arzobispo, fuera conveniente y viable, la cual, aprobada previamente por el señor nuncio, el señor arzobispo patrocinaría ante el gobierno. El señor arzobispo habló y repitió en una y otra forma al señor nuncio ${ }^{68}$ de las gestiones que haría y de las influencias que movería para sacar el concordato. Encargaría a su vicario general que hablara en su nombre al presidente de la República, escribiría a los ministros y aun los llamaría y cuando todo estuviera pronto, entregaría el negocio al señor nuncio para que él lo finiquitara ${ }^{69}$.

"Esperaría el señor arzobispo el $1^{\circ}$ de marzo, día de la llegada de vacaciones de su vicario señor Miller para comenzar con él el estudio y las gestiones.

"El señor nuncio no se cansaba de dar gracias a Dios del nuevo rumbo felizmente auspiciado de la gestión y así lo comunicó a la Santa Sede.

\section{“[10.] Impresión del vicario ${ }^{70}$}

"Aquí anoto un detalle al parecer insignificante, que puede tener su importancia. La gestión reiniciada, aunque dirigida por el señor arzobispo, iba a estar casi por completo en manos de su vicario monseñor Miller. De él, pues, dependería en gran parte el éxito. Conocer su opinión o, más bien, su impresión al llegar era de la mayor importancia. Con franqueza debo decir que, así como algunos ${ }^{71}$ venerables sacerdotes a quienes se había impuesto del asunto para que lo apoyaran ${ }^{72}$, lo habían celebrado con toda el alma, yo temía que en el vicario no encontrara una igual acogida. Sabía que estaba viva la herida del incidente antes expuesto. De ahí mi temor. Para orientarme, encargué a Astorga, el amigo íntimo del vicario, que lo impusiera a su llegada del asunto para saber qué le parecía. A Astorga sólo lo impuse de lo necesario.

"Pronto Astorga me dijo: 'no supo qué decir, se quedó callado pensando; parece que esto lo tomó de nuevo, se desconcertó’.

"Supe esa misma tarde que el vicario recién llegado, había decidido viaje para el día siguiente, yéndose por un mes, hasta Semana Santa, a visitar las parroquias de la costa y que había sido inútil hacerlo desistir. Supe después que fue preciso que el señor arzobispo le pidiera que saliera sólo por ocho días, pues lo necesitaba en Santiago.

\footnotetext{
${ }^{68}$ La expresión "al señor nuncio", está agregada, manuscrita, entre líneas.

${ }^{69}$ La palabra "finiquitara" está manuscrita, entre líneas, sobre la palabra "tramitara" que está tarjada.

${ }^{70}$ En el original con letras mayúsculas.

${ }^{71}$ La palabra "algunos" está manuscrita, entre líneas, sobre la palabra "los", escrita a máquina, que está tarjada.

${ }^{72}$ La frase "para que lo apoyaran" está manuscrita, entre líneas.
} 
"Aprovechando las horas que estuvo en Santiago, yo lo visité en su casa. Una de sus primeras frases fue esta que me dirigió cruzando los brazos: '¿Pero, qué es lo que pasa que encuentro al señor arzobispo tan cambiado con el señor nuncio? Ahora no halla donde ponerlo'. Lo encontré cerrado e inabordable sobre todo el proyecto que se ideaba. Lo único que me dijo fue que el señor arzobispo estaba muy entusiasmado, que le había pedido fuera él el intermediario ante el gobierno, 'pero yo seré un recadero nada más', me agregó.

\section{“[11.] Estudio y gestiones ${ }^{73}$}

"En la segunda quincena de marzo se comenzó el estudio del proyecto del concordato del señor arzobispo. No conozco detalles de este paso. Sé que en esto ha tenido principal intervención el abogado administrador de bienes del arzobispado don Manuel de la Lastra ${ }^{74}$, quien se ha asesorado por los abogados don José Ramón Gutiérrez ${ }^{75}$ y don Exequías Alliende ${ }^{76}$ principalmente.

${ }^{73}$ En el original con letras mayúsculas.

${ }^{74}$ Manuel de la Lastra Cruchaga nació en Santiago el 15 de marzo de 1896; hijo de Alfredo de la Lastra Pérez Cotapos y Virginia Cruchaga Aspillaga. Sus estudios los hizo en el colegio San Ignacio y posteriormente en la Universidad Católica, donde estudió derecho; siendo estudiante recibió el premio universitario "José Tocornal” y en 1917 fue presidente del Centro de Derecho de la Universidad Católica. Al año siguiente se tituló de abogado, el 4 de junio de 1918, después de haber aprobado su tesis que llevó por título La porción conyngal. Fue profesor de derecho civil en la misma Facultad y miembro del consejo superior de la Universidad Católica. Se dedicó al ejercicio de su profesión en Santiago, siendo abogado y administrador general de los bienes del arzobispado de Santiago desde 1920. Se casó en junio de 1922 con Raquel Bernales Lazcano, matrimonio del cual nacieron siete hijos. Entre otras actividades, fue presidente y director de diversas compañías y sociedades. Militante del partido conservador, fue diputado de 1930 a 1934. En 1935 fue elegido regidor de la comuna de Nunñoa y luego alcalde de dicha municipalidad. Fue, además, director de El diario Ilustrado. Véase: Valencia Avaria, Luis, cit. (n. 37), II, pp. 497-499; en la web, Reseñas biográficas parlamentarias.

${ }^{75}$ José Ramón Gutiérrez Martínez nació en Santiago en 1855, hijo de Juan de Dios Gutiérrez y Jesús Martínez. Estudió en el colegio de los Sagrados Corazones ingresando posteriormente a estudiar derecho en la Universidad de Chile; juró como abogado el 20 de junio de 1890. Casado con Carolina Alliende, tuvieron once hijos. Ejerció su profesión de abogado en Valparaíso y Santiago; en esta última ciudad fue profesor de derecho civil en la Facultad de Derecho de la Universidad Católica, de la que fue decano entre 1914 y 1920. Fue un notable periodista, llegando a ser redactor y luego director del diario La Unión, de Valparaíso. Militó toda su vida en el partido conservador. Fue elegido primer alcalde de Valparaíso. Fue electo diputado por Quillota y Limache para el período 1891-1894. Fue nombrado ministro de Industria y Obras Públicas por el presidente Germán Riesco, cartera que desempeñó entre el 21 de octubre al 25 de diciembre de 1905 y del 26 de diciembre de 1905 al 19 de marzo de 1906. Este último año fue elegido diputado por Valparaíso y Casablanca, para el período 1906-1909 y nuevamente electo diputado, pero por La Victoria y Melipilla, para el periodo 1909-1912. Entre el 15 de agosto de 1911 y el 6 de enero de 1912, fue ministro del Interior, durante la presidencia de Ramón Barros Luco. En 1911 se designó una Comisión parlamentaria de colonización y se le confió la presidencia, por lo cual visitó la zona austral. Como resultado de su estudio, la Comisión presentó tres proyectos que servirían después para la solución que se dio en 1928, al problema de la constitución de la propiedad austral. En 1925 realizó una gira a Europa, por motivos de salud y de estudios. Después de este viaje, no reapareció en la escena pública. Vivió en Santiago, dedicado al hogar y a sus lecturas favoritas, el derecho, al tiempo que trabajó en la preparación de un libro. Véase: Valencia Avaria, Luis, cit. (n. 37), pp. 534, 542; en la web, Reseñas biográficas parlamentarias.

${ }^{76}$ Exequías Alliende nació en Santiago en 1879. Además de ejercer la profesión, fue profesor 
"En cuanto a las gestiones, sé que el ministro de Relaciones Exteriores ha manifestado la mejor voluntad y que él está pronto, ha dicho, para finiquitar el asunto; que el presidente de la República ha manifestado muy buenas disposiciones y se le ha hecho saber al señor arzobispo, que ha dicho 'que si se presentan dificultades, se les buscará la solución', que el presidente encargó al obispo mons[eñor] Rücker ${ }^{77}$ 'que dijera a los dignatarios de Roma que aprovecharan su gobierno para sacar este asunto, pues él tiene voluntad de solucionar este problema, aunque tiene mil otros encima, que después no se sabe lo que vendrá'.

"El parecer, pues, del presidente y del ministro de Relaciones Exteriores se ha conocido bien. El primero ha tenido siempre buena voluntad a este asunto, salvo el momento en que, influenciado por el ministro de Hacienda con los fines antes dichos, suspendió las negociaciones. El segundo ha manifestado en todo momento su acuerdo. Sobre los otros ministros nada se sabe. El señor Miller ha guardado un secreto absoluto sobre el particular. Si los ha visto o no los ha visto; si ha sostenido ante ellos los puntos de vista de la Iglesia o no los ha sostenido, todo eso es un misterio impenetrable. Nadie lo sabe.

"El proyecto estudiado por el señor arzobispo fue presentado al señor nuncio para su consideración el día [blanco] de abril por los señores Miller y De la Lastra.

"Cambiaron ideas largamente y el señor nuncio se manifestó de acuerdo.

"El señor Miller le manifestó en esa entrevista que ese documento contenía lo que el señor arzobispo creía poder obtener y que ahora, al entregarlo al gobierno, el señor nuncio podía ver si era posible obtener más.

"El proyecto pasó, pues, al gobierno, el día [blanco] de abril, estando de cuerdo el señor arzobispo con el señor nuncio sobre él y en libertad el señor nuncio para procurar obtener más ventajas.

\section{“[12.] La primera piedra en el camino ${ }^{78}$}

"El 12 de abril llegué por la mañana a la nunciatura y encontré al señor nuncio en su escritorio particular sumamente preocupado. Su semblante mismo lo

de derecho comercial en la Escuela de Derecho de la Universidad Católica de Chile. Fue abogado del Banco Central de cuyo ordenamiento jurídico fue autor. Participó también en la Comisión de cambios internacionales. Fue abogado integrante de la Corte Suprema. Falleció en 1938. Véase: Guía del poder judicial y foro de Chile (Santiago, 1931), p. 355.

${ }^{77}$ Martín Rücker Sotomayor nació en Santiago el 26 de enero de 1867. Fue ordenado sacerdote el 20 de diciembre de 1890 después de cursar sus estudios en el Seminario de Valparaíso. Fue vicario apostólico de Tarapacá, vicario general del arzobispado de Santiago, rector de la Universidad Católica de Chile y decano de la Facultad de Teología. Pío XI (1922-1939) lo eligió gobernador eclesiástico de Chillán y obispo titular de Mariamés el 16 de marzo de 1923, siendo consagrado en la catedral de Burgos, España, por el cardenal Juan Benlloch y Vivó, arzobispo de Burgos; tomó posesión el 27 de enero de 1924. Al ser creada la diócesis de Chillán, Pío XI lo eligió su primer obispo en el consistorio del 14 de diciembre de 1925. Tomó posesión de la diócesis el 25 de abril de 1926. Falleció en Chillán el 6 de enero de 1935. Está enterrado en la catedral de Chillán. Lo sucedió Jorge Larraín en 1937. Véase: Cárdenas Medina, Robinson, Martin Rücker, primer obispo de Chillán, en Anuario de Historia de la Iglesia en Chile, 3 (1985), pp. 43-67; DuCASSE Medina, Ignacio, cit. (n. 20), pp. 253-254; LeÓn L., Marco Antonio, Martín Rücker Sotomayor y el vicariato apostólico de Tarapacá, en Anuario de Historia de la Iglesia en Chile, 16 (1998), pp. 103-127; Oviedo CAVADA, Carlos, cit. (n. 20), pp. 202-203;

${ }^{78}$ En el original con letras mayúsculas. 
reflejaba. Le hablé de un asunto cuyos detalles yo sabía que le interesaban en alto grado y apenas prestó atención a él. Algo grave sucedía y pronto su excelencia me lo explicó. En esa misma mañana, hacía media hora, había estado a visitarlo monseñor Carlos Casanueva, rector de la Universidad Católica ${ }^{79}$. El señor Casanueva le había referido íntegramente una entrevista que había tenido con el señor arzobispo la tarde anterior. Los detalles de esta entrevista yo los conocí tanto por la referencia del señor nuncio, como por el mismo señor Casanueva. En resumen, el señor arzobispo estaba muy disgustado con el señor nuncio: 'se le había comunicado que el señor nuncio a espaldas suyas había presentado un nuevo proyecto de concordato al gobierno; que, siendo lo convenido que el señor arzobispo estudiaría el proyecto que considerara viable y habiéndose ya redactado el proyecto, habiéndole consultado al señor nuncio, quien se manifestó de acuerdo con él y presentado al gobierno, esta actitud del señor nuncio significaba una falta de sinceridad. Que había, además, la circunstancia de que el señor nuncio ni una palabra había dicho al señor arzobispo de que él presentaría un proyecto distinto, siendo que, hasta el día anterior, el señor nuncio lo había visitado y que, aún sabía que de su casa se había ido a la Moneda a gestionar su proyecto. Que en estas condiciones él no continuaba adelante y no daría un paso más'. Este es el resumen de lo que el señor arzobispo expresó al señor Casanueva y que él transmitió in extenso al señor nuncio.

"Las primeras impresiones del señor nuncio ante un hecho tan grave que envolvía el fracaso del concordato y un posible rompimiento con el arzobispado, fueron de profunda amargura y a la vez de desconcierto. Para lo primero le sobraba razón.

\section{“[13.] El cardenalato ${ }^{80}$}

"El respeto y el aprecio que el señor nuncio ha tenido en todo momento por el señor arzobispo puede confirmarse por este hecho. En los primeros días de abril, los diarios daban la noticia del posible cardenalato del señor arzobispo de Buenos

\footnotetext{
${ }^{79}$ Carlos Casanueva Opazo nació en Valparaíso el 21 de septiembre de 1874, hijo de Carlos Casanueva Ramos e Isabel Opazo Bello, nieta de Andrés Bello, por lo que era bisnieto del gran jurista. A los 7 años su familia se trasladó a Santiago, estudiando en el colegio francés de Monsieur Grosseling y posteriormente en el colegio San Ignacio. Estudió derecho en la Universidad de Chile y, al mismo tiempo, economía social en la Universidad Católica. Se recibió de abogado en 1896, ingresando posteriormente al Seminario de Santiago, para ser ordenado presbítero el 22 de septiembre de 1900 por el arzobispo Mariano Casanova. Su primer nombramiento fue en el patronato Santa Filomena, al otro lado del río Mapocho, en Santiago, donde dos años después inauguró una nueva capilla. En 1910 se le encargó la dirección espiritual del Seminario, puesto que sirvió hasta 1919, año en que el arzobispo Errázuriz, partidario de cerrar la Universidad Católica, lo nombró rector interino de la misma, nombrándolo en propiedad el 1920. Permaneció al frente de la Universidad por 23 años, bajo cuyo rectorado creció con nuevas facultades, como Medicina (1930), Teología (1935), además del hospital clínico (1939); de su época es el club deportivo Universidad Católica (1928). En 1923 fue nombrado canónico honorario del cabildo catedralicio y en 1935 protonotario apostólico. Renunció como rector en 1953 por razones de salud, falleciendo el 31 de mayo de 1957. Véase: HeVIA Fabres, Pilar, El rector de los milagros. Don Carlos Casanueva Opazo (Santiago, 2004); Arancibia Salcedo, Raymundo, cit. (n. 28), pp. 45-46.

${ }^{80} \mathrm{En}$ el original con letras mayúsculas.
} 
Aires. El señor nuncio me preguntó una mañana mi opinión sobre la conveniencia de gestionarlo para el señor arzobispo de Santiago. Se la di ampliamente afirmativa y él, con entusiasmo, me manifestó que había pensado que, siendo éste un anhelo antiguo de la opinión católica chilena y sabiendo que el gobierno daría algunos pasos en ese sentido, era el momento de informar a la Santa Sede y recordar las razones que abonaban ese deseo.

"Al día siguiente me dijo el señor nuncio que ya había puesto un cable a la Santa Sede de 150 palabras sobre el particular.

"Se comprenderá, pues, conociendo hechos como éste que demuestran la lealtad y el aprecio del señor nuncio hacia el señor arzobispo, la amargura que le causó no sólo la injusticia como se verá más adelante, sino la ingratitud que envolvían las duras expresiones del señor arzobispo para juzgarlo.

"Una vez más pude admirar en él al sacerdote que ofrecía estos dolores, ante la imagen de Nuestro Señor, por el bien de su Iglesia.

"[14.] El nudo de la cuestión ${ }^{81}$

“Cuál era el concordato nuevo que el señor arzobispo creía que el señor nuncio había presentado al gobierno a sus espaldas? He aquí los hechos:

“Después que los señores Miller y De la Lastra presentaron al señor nuncio el proyecto del señor arzobispo, quedando él de acuerdo y en libertad para procurar obtener algo más, el proyecto pasó al gobierno. Parece que el gobierno distribuyó los artículos en los diversos ministerios para que cada ministro se pronunciara sobre la materia pertinente. Al ministerio del Interior, servido por don Guillermo Edwards ${ }^{82}$, pasó el artículo $2^{\circ}$, relacionado con el reconocimiento de la Iglesia como institución de derecho público; al de Justicia, el relacionado con el matrimonio; al de Instrucción, el de la enseñanza; al de Hacienda, el de las contribuciones, etc.

"Se conocía por esos días ya la opinión del ministro Edwards Matte, rotundamente adversa al reconocimiento de la Iglesia con personería de derecho público,

${ }^{81}$ Ídem.

${ }^{82}$ Guillermo Edwards Matte nació en Santiago el 23 de octubre de 1889, hijo de Guillermo Edwards Garriga y de Rosario Matte Pérez. Se casó con María Hurtado Quesney, con quien tuvo 5 hijos. Estudió en el Instituto Nacional, posteriormente, en la Facultad de Derecho de la Universidad de Chile, jurando como abogado el 12 de enero de 1912. Se dedicó a las actividades profesionales propiamente tal, a las periodísticas y agrícolas, en su fundo "Lo Valdivieso", donde hoy se sitúa el estadio nacional. Fue militante del partido liberal y vicepresidente del partido liberal-unionista en 1925. En 1918 fue electo diputado por Victoria, Melipilla y San Antonio, período 1918-1921; fue presidente de la Cámara, el 18 de noviembre hasta el 9 de diciembre de 1920. Fue reelecto diputado, pero por Rancagua, Cachapoal y Maipo, período 1921-1924. Integró la comisión y subcomisión que redactaron la Constitución de 1925. Durante el gobierno de Arturo Alessandri fue ministro de Hacienda, desde el 29 de agosto hasta el 21 de diciembre de 1922, y nuevamente ministro de Hacienda, del 2 de octubre hasta el 23 de diciembre de 1925. Posteriormente, durante el gobierno de Carlos Ibáñez del Campo fue nombrado ministro del Interior el 5 de junio de 1928, ministerio que desempeñó hasta el 30 de agosto de 1929, día en que asumió Enrique Bermúdez. Ocupó el cargo de director en diversas sociedades y compañías. Falleció en Santiago el 16 de agosto de 1945. Véase: Valencia Avaria, Luis, cit. (n. 37), pp. 576-577; en la web, Reseñas biográficas parlamentarias. 
fundado, según el ministro, en el espíritu del artículo $10^{\circ}$ de la Constitución del año 25 .

"En la redacción del proyecto del señor arzobispo se había dado a este punto una solución (ideada por don José Ramón Gutiérrez) en que, sin declarar a la Iglesia nominativamente como persona de derecho público, se le reconocía tal carácter en las consecuencias. Era éste el único punto del proyecto de concordato en que el señor nuncio no estaba en completo acuerdo con el señor arzobispo. Así se lo había manifestado a los señores Miller y De la Lastra. Deseaba Su Excelencia más explícito reconocimiento; pero, en último caso aceptaba también la fórmula del señor arzobispo.

"El proyecto, ya en el gobierno para su estudio, y libre el señor nuncio para tramitarlo ahí y procurar mayores ventajas, llegó el [blanco] de abril a la Moneda a conversar con el subsecretario de Relaciones Exteriores, don Nicolás Novoa Valdés, a quien le cabía importante actuación en el asunto.

"En esta entrevista dijo el señor nuncio al señor Novoa: 'por un momento no es usted el subsecretario de Relaciones Exteriores, sino el católico que yo conozco y yo no soy el nuncio, sino un obispo que quiere el mayor bien para la Iglesia; dígame, mi amigo, ¿considera usted que la redacción de este artículo $2^{\circ}$ deja bien asegurados los intereses de la Iglesia, o bien quedarían mejor agregando esta frase?' Y le dictó la corta frase que daba una forma más explícita al artículo. El señor Novoa la anotó con lápiz en un papel; el señor nuncio le pidió que viera, si era posible y viable esa fórmula que le sugería privadamente.

"El señor Novoa por su propia cuenta e inspiración, redactó en tres grandes hojas de papel un memorándum que decía: Concordato. Proyecto de la nunciatura. Proyecto del arzobispado ${ }^{83}$. Este doble proyecto lo envió con una tarjeta de suma reserva al vicario señor Miller.

"En la tarde de aquel día en que el señor nuncio me refirió lo que pasaba y me confirmó el señor Casanueva, visité al señor Miller. Comprendí que era menester comenzar por ahí a desenredar la madeja. Expresé al señor Miller que el señor nuncio desgraciadamente conocía todas las duras expresiones con que lo juzgaba el señor arzobispo; le expuse detalladamente cuál era la única innovación que particularmente había pedido, si era posible, introducir en el proyecto del señor arzobispo y le hice ${ }^{84}$ ver la necesidad de aclarar este asunto que podía tomar un sesgo muy grave. El señor Miller me mostró la carta del señor Novoa y el memorándum del doble proyecto; al leer sus títulos, me impresioné profundamente. Comencé ávidamente su lectura. El artículo $1^{\circ}$ era exactamente igual; el artículo $2^{\circ}$ contenía como diferencia, la frase que había indicado el señor nuncio al señor Novoa; el artículo $3^{\circ}$, el $4^{\circ}$, el artículo $5^{\circ}$ todos iguales, salvo alguna palabra sin importancia, comas más, comas menos. Respiré.

“¿Pero dónde estaba ese doble proyecto de concordato que amenazaba con ${ }^{85}$ una tempestad?

"Me limité a decirle al señor Miller: 'pero, si esto es igual. No hay más diferencia que la que se ha adelantado a señalar el señor nuncio’.

${ }^{83}$ La palabra “Concordato” está subrayada a máquina en el original. El título "Proyecto de la nunciatura. Proyecto del arzobispado” está subrayado a máquina y escrito con letras mayúsculas.

${ }^{84}$ La palabra "hice" está añadida manuscrita entrelíneas.

${ }^{85}$ La palabra “con” está añadida manuscrita entrelíneas. 
"El señor Miller me dijo que no tenía importancia el incidente y que todo seguiría adelante como antes.

"Al día siguiente visité al señor arzobispo quien me recibió en forma extraordinariamente afectuosa. Puestos varios preámbulos, abordé el tema que me interesaba, diciéndome él desde el principio que 'él no sabía nada'; no obstante, le pedí permiso para aclarar actuaciones del señor nuncio que podían llegar mal interpretadas a su conocimiento y, acto seguido, le hice relación detallada de lo que he expuesto antes, recalcándole que el doble proyecto, enviado por el señor Novoa, era tal sólo materialmente porque así lo decían las letras y la división de los papeles, siendo en realidad exactamente iguales, salvo la corta frase que el señor nuncio desde el comienzo aseguró que había sugerido, en uso de sus atribuciones y aún de la libertad en que lo había dejado el señor arzobispo y aún en forma privada.

"Le agregué este detalle también de importancia. Cuando el señor nuncio estuvo aquí, con S[u] S[eñoría] el jueves, efectivamente de aquí se fue a la Moneda. Recibió, al bajar, un llamado telefónico de que se le necesitaba con urgencia en la Moneda. Era el señor Novoa quien lo llamaba para comunicarle que el ministro de Justicia no aceptaba el reconocimiento de los efectos civiles del matrimonio religioso y sólo que se mantuviera al respecto la situación actual y que el ministro de Instrucción aceptaba la enseñanza religiosa en los colegios del Estado, pero pagada por la Iglesia. Antes estas novedades, el señor nuncio manifestó al señor Novoa que era preferible desistir del concordato. Le agregó que en el acto iría a comunicar lo que había al señor arzobispo quien era el que tenía en sus manos las negociaciones y que, sin duda, esto sería un pesar para el prelado. El señor Novoa le pidió que no comunicara nada aún al señor arzobispo para evitarle un desagrado, hasta que él no hablara con cada ministro para procurar avanzar algo. Que él le comunicaría lo que hubiese para que a su vez el señor nuncio lo hablara con el señor arzobispo.

“Esta fue la salida que el señor nuncio hizo de la oficina del señor arzobispo a gestionar a espaldas suyas un nuevo concordato!

"El señor arzobispo me oyó toda la exposición con profunda atención y, sin decir una palabra sobre el incidente, comenzó a hablar en forma entusiasta de las nuevas gestiones que pensaba hacer para sacar el concordato, principalmente sobre el tenaz ministro Edwards Matte. Al día siguiente visitó el señor nuncio al señor arzobispo y éste le repitió sus buenos deseos de seguir adelante hasta el fin $^{86}$. El incidente estaba sepultado.

\section{"[15.] La segunda piedra en el camino ${ }^{87}$}

"En la visita que el señor nuncio hizo al señor arzobispo el jueves 25 de abril, sin mencionar siquiera el incidente del presunto doble concordato, le reiteró el prelado al señor nuncio su resolución de continuar las gestiones con el mayor interés y 'de llegar juntos hasta el fin'.

"Sin mediar explicación alguna directa, el incidente estaba terminado, de hecho. El señor arzobispo con sus declaraciones de continuar adelante demostraba que había reconocido su error.

\footnotetext{
${ }^{86}$ Las palabras "hasta el fin” están agregadas manuscritas entre líneas.

${ }^{87}$ En el original con letras mayúsculas.
} 
“Dos días después, el sábado 27 el señor arzobispo en forma nerviosa decía al señor cura de Santa Ana, don Francisco Javier Valdivia ${ }^{88}$, encargándole expresamente que diera a conocer su opinión, lo siguiente: 'que él estaba en completo desacuerdo con el señor nuncio sobre el concordato, que no se creyera que él tenía la responsabilidad sobre este asunto, que había pedido a su vicario señor Miller que pidiera una audiencia al presidente de la República para hacerle saber el desacuerdo en que estaba con el señor nuncio y que deseaba que esto se conociera'.

"El señor Valdivia, cumpliendo los deseos del prelado, refirió esa misma noche lo que le había oído, en una comida a que asistían 20 personas, entre quienes varios sacerdotes, Juan Francisco Fresno ${ }^{89}$, Ramón Merino ${ }^{90}$, José Antonio Lira ${ }^{91}$,

${ }^{88}$ Francisco Javier Valdivia Pineda nació en Ovalle el 22 de mayo de 1885. Estudió en el Seminario de Santiago y se ordenó presbítero el 25 de diciembre de 1908 . Fue profesor en el Seminario de Santiago y en el de Valparaíso. En 1916 fue nombrado párroco de San Fernando donde permaneció poco más de un año. De regreso en Santiago, fue nombrado director de $L a$ Revista Católica. En 1926 pasó a servir la parroquia de Santa Ana donde permaneció por 23 años. Fue profesor en diversos colegios y en la Escuela Normal Santa Teresa. Sobresalió como buen orador sagrado y escribió un Compendio de historia griega y romana. En 1940 fue nombrado obispo de Linares, pero renunció sin haber sido consagrado. Pío XII lo nombró protonotario apostólico. Una vez que dejó la parroquia Santa Ana, pasó a ser canónico penitenciario del cabildo metropolitano. Falleció en Santiago, el 17 de junio de 1951. Véase: Arancibia Salcedo, Raymundo, cit. (n. 28), pp.204-205.

${ }^{89}$ Juan Francisco Fresno Larraín nació en Santiago el 26 de julio de 1914. Del clero de Santiago. Bachiller en derecho canónico por la Pontificia Universidad Gregoriana de Roma. Pío XII (1939-1958) lo eligió primer obispo de la recién creada diócesis de Copiapó el 15 de junio de 1958, tomando posesión de la diócesis el 26 de agosto de 1958. Paulo VI (1963-1978) lo promovió como cuarto arzobispo de La Serena el 28 de junio de 1967. Participó en las cuatro sesiones del Concilio Vaticano II. Juan Pablo II (1978-2005) lo trasladó como noveno arzobispo de Santiago el 6 de mayo de 1983, sucediendo al cardenal Raúl Silva Henríquez que había renunciado por razón de edad. Juan Pablo II lo creó cardenal presbítero en el consistorio del 25 de mayo de 1985 con el título de Santa María Inmaculada de Lourdes a Boccea. Renunció al arzobispado de Santiago por razón de edad en julio de 1989. Adoptó el título de arzobispo emérito de Santiago. Falleció el 14 de octubre de 2004. Véanse: AA. VV., Cardenal Juan Francisco Fresno Larrain. Un pastor para Chile (Santiago de Chile, 1969); Ducasse Medina, Ignacio, cit. (n. 20), pp. 156-158; FALCH F., Jorge, Cardenal Juan Francisco Fresno Larraín *26-7-1914 +14-10-2004, en La Revista Católica, 104 (2004), 1144, pp. 350-352; Oviedo Cavada, Carlos, cit. (n. 20), pp. 122-123.

${ }^{90}$ Ramón Merino hizo sus estudios en la sección seglar del Seminario de Santiago donde sufrió un accidente deportivo que le significó perder una mano; después continuó sus estudios en la Universidad donde se tituló de abogado. En Valparaíso fue director del diario La Unión. Sintiéndose llamado al sacerdocio, ingreso al Seminario de Santiago donde inició sus estudios para el sacerdocio, los que continuó en el Colegio Pío latino, en Roma, ciudad en la que, previa dispensa de la Santa Sede, fue ordenado presbítero el 25 de marzo de 1915; su primera Misa la celebró en la Basílica de San Pedro. A partir de 1917, fue profesor en el Seminario, cura de Melipilla y capellán de la Iglesia de las agustinas. Organizó el dinero del culto, del que fue su primer director; fue también secretario general de la Acción Católica. Durante un tiempo fue vicario general de la administración apostólica de Valdivia. De regreso en Santiago fue visitador diocesano y director de la Casa de San Juan Evangelista. Falleció en Santiago, el 15 de junio de 1944. Véase: Arancibia Salcedo, Raymundo, cit. (n. 28), p. 138.

${ }^{91}$ José Antonio Lira nació en Santiago el 7 de diciembre de 1874 . Fue ordenado presbítero el 22 de septiembre de 1906. Fue profesor y ministro del Seminario de Talca, administrador del cementerio católico, capellán del Buen pastor y contador diocesano por espacio de trece años. 
Manuel Menchaca92. Ramón Merino al día siguiente comunicó in extenso el incidente al señor nuncio.

“[16.] El completo desacuerdo ${ }^{93}$

"Para desenredar la nueva madeja, visité primero al señor Miller. Estaba irritado por la facilidad con que 'se llevaban los cuentos'. Le encontré razón, mala es la indiscreción, pero, más importante era saber en qué consistía 'el completo desacuerdo' en que decía el señor arzobispo que estaba con el señor nuncio.

"Me explicó que el señor arzobispo estaba muy nervioso, que no dormía, que en un momento de mal humor había lanzado esas frases que no debía haber repetido Valdivia, mi menos Merino. Pero, ¿y el fundamento de ellas? Me dijo que el señor arzobispo había oído que el señor nuncio había cedido completamente en el artículo $2^{\circ}$ del proyecto del concordato, en el reconocimiento de la Iglesia con personería de derecho público y que ahora aceptaba que quedara como institución de derecho privado. Al oír esto, no pude contenerme y me reí. Me dijo el vicario: 'U[ste]d se ríe porque habrá oído al señor nuncio lo contrario'. 'Exactamente y no una vez, sino que cien veces y porque este mismo asunto pero exactamente al revés fue el fundamento del incidente anterior. El señor nuncio no creía bastante explícita la fórmula anterior, quería más precisión y ahora se cree que piensa al revés'.

"Hablé enseguida largamente con De la Lastra, quien me repitió exactamente lo que me había dicho el vicario; pero, me agregó un dato curioso. La nerviosidad del señor arzobispo provenía principalmente de que el gobierno no le había contestado una palabra, se había puesto candado en los labios desde hacía 20 días, o sea desde que había entregado el proyecto. Temía, por tanto, que fracasara y De la Lastra lo creía ya fracasado.

"Visité al señor nuncio al día siguiente. Poco pude decirle y oírle. Su estado de ánimo era de profundo desaliento.

"Al día siguiente, me explicó detenidamente su pensamiento sobre el punto de la personería de la Iglesia. Él había sido invariable, era el punto único en que se había mantenido inflexible; días antes había dicho al señor Novoa: 'yo me dejaría cortar la mano antes que firmar un tratado en que no se reconozca a la Iglesia como institución de derecho público'. El señor Novoa le había mostrado una carta del embajador de la Santa Sede, señor Subercaseaux, en que decía al ministro de Relaciones Exteriores que: 'la Santa Sede podría estar dispuesta a conceder que no reconociera la personería de derecho público de la Iglesia'. El señor nuncio, al

Fue párroco fundador de la parroquia de San Juan Evangelista (1928). Falleció en Santiago, el 16 de noviembre de 1937. Ibíd., p. 122.

${ }^{92}$ Manuel Menchaca nació en Concepción en 1896. Siendo alumno del Seminario conciliar de Santiago se trasladó a Concepción en 1918, acompañando a Gilberto Fuenzalida Guzmán, recién nombrado obispo de Concepción. Recibió el presbiterado el 19 de abril de 1919, desempeñándose como profesor y ministro del Seminario de Concepción; fue también prosecretario del obispo. Posteriormente, en Santiago fue asesor de los estudiantes católicos, profesor del Liceo Amunátegui y director de la obra de Propaganda fide. La Santa Sede le nombró prelado doméstico de Su Santidad. Falleció en Santiago en 1959. Ibíd., pp. 136-137.

${ }^{93}$ En el origina con letras mayúsculas. 
conocer el documento, dijo al sub-secretario: 'me parece que el embajador puede no haber interpretado bien el pensamiento de la Santa Sede'.

"Llegando a la nunciatura puso un cable al cardenal secretario de Estado, dándole cuenta del contenido de la nota del embajador, pidiéndole le dijese qué sabía sobre el particular y anunciándole que enviaba carta. Esa carta fue un documento de ocho carilla en que, en forma silogística, exponía al cardenal las razones que aconsejaban no ceder en la personería de la Iglesia.

"Visité de nuevo al señor Miller. El señor Miller de nuevo hizo nada el incidente. Me dijo que el señor arzobispo sostenía que no había dicho nada a Valdivia sobre desacuerdo con el señor nuncio. Le repuse que con ese sistema no se aclaraban las cosas, ni se solucionaban las dificultades, sino que iba quedando un residuo de desconfianza y desinteligencias cuyas consecuencias podrían ser graves. Que, mientras se decía que 'no se había dicho nada' y que 'esto era nada', el nombre del señor nuncio corría de boca en boca y su prestigio quedaba por los suelos, fundándose esos juicios en la autoridad del propio señor arzobispo. Y mientras tanto ¿̨cuál era el fundamento que tenía el señor arzobispo para lanzar a la publicidad 'el perfecto desacuerdo'? Y le hice, al respecto, una detallada exposición de lo dicho anteriormente y le agregué que tenía encargo del señor nuncio de que esto llegara, por su conducto, a conocimiento del señor arzobispo. El señor Miller me habló entonces con optimismo de las gestiones que iba a hacer, de que pediría al ministro de Relaciones Exteriores lo acompañara hasta el presidente de la República 'para cobrarle la palabra a favor del concordato', etc. ‘¿De manera que no será la entrevista con el presidente para comunicarle 'el completo desacuerdo' de que habla el señor arzobispo?', le dije. Protestó de mi pregunta. 'Dios lo quiera, le dije, pero, lo que me parece importante por ahora es que, si esas gestiones no resultan, como parece, no se agregue a esa desgracia, otra más que puede ser de consecuencias' (y le subrayé esta palabra), pues se ve que esto camina a un rompimiento entre el arzobispo y el señor nuncio y para ello no hay ningún fundamento. 'Si el concordato fracasa, le agregué, lo correcto y sacerdotal es que caigan juntos el señor arzobispo y el señor nuncio. Dios no lo ha querido y nada más'. Terminó el señor Miller con el mejor de los optimismos, declarando que estos incidentes eran 'nada' y que el concordato saldría.

"Ese mismo día, el señor nuncio visitó al señor arzobispo. Le dijo al comenzar más o menos: 'Excelencia, siento decirle que me llegan rumores de apreciaciones que V[uestra] E[xcelencia] encarga que se sepan y que a mí me han llenado de amargura. Estos juicios se refieren a desacuerdos completos que habría entre V[uestra] E[xcelencia] y yo y deseo conocer en qué consisten, pues mi conciencia nada me dice sobre el particular'. El señor arzobispo tomó largamente la palabra. Le aseguró que: 'él nada había dicho de desacuerdos que no existían', que marchaban en completa armonía y así seguirían marchando hasta el fin, que de lo único que se había quejado era de que se le creyera a él el tramitador y responsable de las gestiones del concordato; pues esto iba en desmedro de la dignidad del señor nuncio, a quien él solamente prestaba una sincera ayuda. Le reiteró una y otra vez su deseo de continuar las gestiones hasta el fin.

"El residuo queda en el fondo. En la mañana del 5 de mayo visité al señor 
arzobispo. Me recibió con gran cordialidad. Como siempre, después de muchos temas de preámbulo, llegamos al asunto capital. Le pregunté si el señor Miller le había explicado cual era el pensamiento del señor nuncio acerca del punto de reconocimiento de la Iglesia como institución de derecho público o simplemente privado, asunto que, sabía, había ocasionado algunas dudas a S[u] S[eñoría]. Me contestó que el señor Miller 'nada le había dicho'. Yo recordé para mis adentros que el viernes había hablado con el señor Miller sobre el particular y que el domingo el señor arzobispo nada sabía; recordé, además, que yo le había pedido al señor Miller, a nombre del señor nuncio, que impusiera al señor arzobispo de lo tratado en la conversación. Nada se había hecho. Comencé entonces a exponer al señor arzobispo las ideas del señor nuncio sobre el asunto; le acentué cuán invariable había sido su opinión al respecto y le dí las mismas pruebas que confirmaban hasta la evidencia que el señor nuncio jamás había cambiado de parecer al respecto y que había dado el viernes al vicario.

"Oyó el prelado con mucha atención y se manifestó satisfecho de la explicación. En seguida, me refirió la entrevista que había tenido él con el señor nuncio el viernes, con los mismos detalles que he apuntado anteriormente. Me recalcó mucho que de lo único que él se había quejado era de que se le creyera el autor y responsable de estas gestiones; que él no era; pues, al serlo, heriría en su dignidad al señor nuncio y eso iría en contra del prestigio de $S[\mathrm{u}] \mathrm{E}$ [xcelencia] que, además, a sus años él no podía tomar esas responsabilidades; que era simplemente una ayuda, un intermediario, que 'era la cañería, pero no el agua que moja'.

"Yo lo oí en silencio. Anotaba en mi interior la diferencia de hoy a un más atrás. Un mes atrás, hablaba con fervoroso entusiasmo del estudio del proyecto que él haría ${ }^{94}$, de los pasos que él daría ${ }^{95}$ para que el gobierno lo aceptara, de que una vez terminado todo, se lo entregaría el negocio al señor nuncio para finiquitarlo. Ahora el concordato parecía hacerle el efecto de una brasa de fuego en la mano. Cuando sentía optimismo y creía en el éxito, asumía él casi íntegra la responsabilidad; cuando estaba pesimista y temía el fracaso, quería traspasar al señor nuncio esa responsabilidad y se fundaba, para ello, en deslealtades del señor nuncio o en divergencias de opinión con él que no han existido jamás.

"Continuó hablando de que creía que el concordato no salía, que ya estaba fracasado, que, a pesar de los buenos deseos manifestados por el presidente y el ministro de Relaciones Exteriores, creía que había influencias ocultas que se oponían y que en el gobierno había temor ${ }^{96}$, había cobardía.

"Era la sepultura a la vista. Al salir, me encontré con el señor Miller y sumariamente le dije lo que había hablado con el señor arzobispo, le referí la explicación que le dí sobre la última presunta divergencia con el señor nuncio, 'explicación, le agregué, que yo creí que U[ste]d le habría dado al señor arzobispo, como convenimos el viernes, pero que, él me dijo, no conocía'. El señor Miller guardó profundo silencio sobre el particular y pasó a otro tema”.

\footnotetext{
${ }^{94}$ Las palabras “él haría” están escritas con mayúscula y subrayadas a máquina.

${ }^{95}$ Las palabras "él daría” están escritas con mayúscula y subrayadas a máquina.

${ }^{96}$ La palabra "temor" está manuscrita encima de la palabra "Señor" escrita a máquina.
} 


\section{BiBLIOGRAFÍA}

AA. VV., Cardenal Juan Francisco Fresno Larrain. Un pastor para Chile (Santiago de Chile, 1969).

Arancibia Salcedo, Raymundo, Diccionario biográfico del clero secular de Chile: 19181969 (Santiago, 1969), \}

Araneda Bravo, Fidel, Historia de la Iglesia en Chile (Santiago, Paulinas, 1986).

Bolletino della Sala Stampa della Santa Sede, 30 junio 2006 N $^{\circ} 0340$, en www.vatican. va [consultado el 24 de mayo de 2011].

Cárdenas Medina, Robinson, Martin Rücker, primer obispo de Chillán, en Anuario de Historia de la Iglesia en Chile, 3 (1985).

De Ramón, Armando y otros, Biografías de chilenos. Miembros de los poderes Ejecutivo, Legislativo y Judicial (Santiago, 2003), IV.

Ducasse Medina, Ignacio, Servidores del Evangelio. Los obispos de Chile 1561-2007 (Santiago, 2008).

Enchiridion dei concordati. Due secoli di storia dei rapporti Chiesa-Stato (Bologna, 2003)1

FALCH F., Jorge, Cardenal Juan Francisco Fresno Larrain *26-7-1914 +14-10-2004, en La Revista Católica, 104 (2004) 1144.

GonzÁlez Errázuriz, Juan Ignacio, El Estado de Chile ante la Iglesia católica. ¿Existió un concordato en 1925?, en Ius Publicum, 5 (2000).

Guía del poder judicial y foro de Chile (Santiago, 1931).

Hevia Fabres, Pilar, El rector de los milagros. Don Carlos Casanueva Opazo (Santiago, 2004).

LeÓn L., Marco Antonio, Martín Rücker Sotomayor y el vicariato apostólico de Tarapacá, en Anuario de Historia de la Iglesia en Chile, 16 (1998).

LirA, Alejandro, Memorias (Santiago, 1950).

Minnerath, Roland, L'Église catolique face aux États. Deux siècles de pratique concordataire 1801-2010 (Paris, 2012).

Oviedo Cavada, Carlos, La jerarquía eclesiástica y la separación de la Iglesia y el Estado en 1925, en Boletín de la Academia Chilena de la Historia, 89 (1975-1976).

Oviedo Cavada, Carlos, La misión Irarrázabal en Roma 1847-1850 (Santiago, 1962).

Oviedo Cavada, Carlos, Negociaciones chilenas sobre convenios con la Santa Sede, en Finis Terrae, 19 (1958).

Oviedo Cavada, Carlos, Un siglo de relaciones entre la Santa Sede y Chile, 1822-1925, en Diplomacia, 39 (1987).

Retamal Fuentes, Fernando, Chilensia pontificia. Monumenta Ecclesiae Chilensia (Santiago, 2005), II, 3.

Salinas Araneda, Carlos, Un primer proyecto de concordato entre Chile y la Santa Sede en 1928, en Revista Chilena de Derecho, 39 (2012) 3.

Stella, Giordano, Pio XI il Papa dei concordati (Milano, 2009).

Valencia Avaria, Luis, Anales de la República (2a edición, Santiago, Andrés Bello, 1986), I. 